OPEN ACCESS

Edited by:

Danie/ M. Johnson,

The Open University, United Kingdom

Reviewed by:

Chengming Fan,

Central South University, China

Rosa Doñate Puertas,

INSERM U1180 Signalisation et

Physiopathologie

Cardiovasculaire, France

*Correspondence:

Wenging Zhu

zhuwqsci@163.com

tThese authors have contributed equally to this work

Specialty section: This article was submitted to

Cardiac Rhythmology,

a section of the journal

Frontiers in Cardiovascular Medicine

Received: 24 September 2021

Accepted: 26 October 2021

Published: 01 December 2021

Citation:

Chen C, Chen Q, Cheng K, Zou T,

Pang $Y$, Ling $Y, X u Y$ and Zhu $W$

(2021) Exosomes and Exosomal

Non-coding RNAs Are Novel Promises for the Mechanism-Based Diagnosis and Treatments of Atrial Fibrillation. Front. Cardiovasc. Med. 8:782451.

doi: 10.3389/fcvm.2021.782451

\section{Exosomes and Exosomal Non-coding RNAs Are Novel Promises for the Mechanism-Based Diagnosis and Treatments of Atrial Fibrillation}

\author{
Chaofeng Chen ${ }^{\dagger}$, Qingxing Chen ${ }^{\dagger}$, Kuan Cheng, Tian Zou, Yang Pang, Yunlong Ling, Ye Xu \\ and Wenqing Zhu*
}

Department of Cardiology, Zhongshan Hospital, Fudan University, Shanghai, China

Atrial fibrillation (AF) is the most common arrhythmia worldwide and has a significant impact on human health and substantial costs. Currently, there is a lack of accurate biomarkers for the diagnosis and prognosis of AF. Moreover, the long-term efficacy of the catheter ablation in the AF is unsatisfactory. Therefore, it is necessary to explore new biomarkers and treatment strategies for the mechanism-based AF. Exosomes are nano-sized biovesicles released by nearly all types of cells. Since the AF would be linked to the changes of the atrial cells and their microenvironment, and the AF would strictly influence the exosomal non-coding RNAs (exo-ncRNAs) expression, which makes them as attractive diagnostic and prognostic biomarkers for the AF. Simultaneously, the exo-ncRNAs have been found to play an important role in the mechanisms of the AF and have potential therapeutic prospects. Although the role of the exo-ncRNAs in the AF is being actively investigated, the evidence is still limited. Furthermore, there is a lack of consensus regarding the most appropriate approach for exosome isolation and characterization. In this article, we reviewed the new methodologies available for exosomes biogenesis, isolation, and characterization, and then discussed the mechanism of the AF and various levels and types of exosomes relevant to the AF, with the special emphasis on the exo-ncRNAs in the diagnosis, prognosis, and treatment of the mechanism-based AF.

Keywords: exosome, non-coding RNAs, atrial fibrillation, diagnosis, treatment

\section{INTRODUCTION}

Atrial fibrillation (AF) is a most common type of cardiac arrhythmia and a global burden with significant morbidity, mortality, and socioeconomic problem $(1,2)$. The AF affects $1-1.5 \%$ of the population worldwide, the frequency of the condition is closely related to advancing age, and its prevalence is expected to more than double over the next 40 years $(3,4)$. Catheter ablation is an established treatment for AF, especially for paroxysmal AF (PAF). However, the success rate for the persistent AF (PsAF) is not ideal because the procedure is often accompanied by risks and other pathological complications. Moreover, there is a lack of effective upstream management for the AF (5-7).

Extracellular vesicles (EVs) include exosomes [diameter range (DR): $30-150 \mathrm{~nm}$ ], microvesicles (DR: $50-1,000 \mathrm{~nm}$ ) and apoptosomes (DR: $50-5,000 \mathrm{~nm}$ ) (8). Exosomes are found in almost 
all body fluids (9-11). They normally contain lipids, proteins, and various RNAs, depending on the cells type and the cellular microenvironment $(12,13)$. Initially, exosomes were believed to be excretory vehicles to discard the metabolic waste but are now regarded as intercellular communicators that shuttle genetic information and proteins between cells $(14,15)$. The exosomal cargoes not only reflect the disease state, but also the physiological process of the receptor cells. Therefore, they can serve as unique biomarkers of developmental processes and prognostics/diagnostics of the disease states (16). Recently, the role of exosomes in cardiovascular diseases has been extensively studied, mainly in in the acute myocardial infarction (AMI), congestive heart failure (CHF), and coronary atherosclerotic disease (CAD), however, comprehensive elucidations on arrhythmia, especially on the AF are limited $(17,18)$. This review aimed to analyze the current knowledge regarding the exosomes' formation, isolation, biological functions, and advancements in the medical application, including potential diagnostic and therapeutic use in the AF.

\section{EXOSOME}

\section{Exosome Biogenesis}

Exosome biogenesis and generation depend on the cell types or cellular microenvironments $(19,20)$. The exosome biogenesis is schematized in Figure 1.

Exosomes are formed by two invaginations of the plasma membrane. The first invagination generates early endosomes in the cytoplasm. The early endosomes mature into late endosomes, whose secondary invagination forms intraluminal vesicles (ILVs). Late endosomes and then finally form multivesicular bodies (MVBs). However, not all ILVs are released as exosomes and some of them would fuse with lysosomes and undergo degradation $(21,22)$. The exosome formation is tightly regulated by the endosomal sorting complex required for transport (ESCRT) and ESCRT-independent pathways. Exosome cargoes include proteins, lipids, and nucleic acids (23). In addition, nucleic acids especially non-coding RNAs (ncRNAs) serve as important cargoes and mediate cells communication (24-26). At present, the mechanisms underlying the cargoes sorting remain unclear.

The detailed mechanism of the MVBs intravesicular trafficking and fusion with the plasma membrane remains elusive. The known proteins involved are SNAREs, Rabs family (RAB27, RAB11, and RAB35), and Ras GTPase (27-30). The intravesicular trafficking may be mediated by the calciumdependent Rabs family and the fusion process may be mediated by the SNAREs proteins $(20,25,31)$. Exosomes are released into the extracellular space after fusion with the membrane. The release of the MVBs occurs in a calcium-dependent manner.

\section{Exosome Uptake}

Possible consequences following the exosomes release include: (1) capture by the neighboring cells or re-absorption by their secretory cells; (2) remote relocation, recognition and fusion with the recipient cells membrane; (3) entry into the circulation and translocation to the other organs (32). However, the underlying mechanisms of the exosome uptake by the recipient cells remain debatable. As reported, there are three suggested mechanisms of uptake: internalization, direct fusion and receptor-ligand mediated uptake (33-40). Thereby, although the precise mechanism of exosome uptake is unclear, one fact remains obvious: the exosomes participate in cells communication through a complex intercellular exchange of

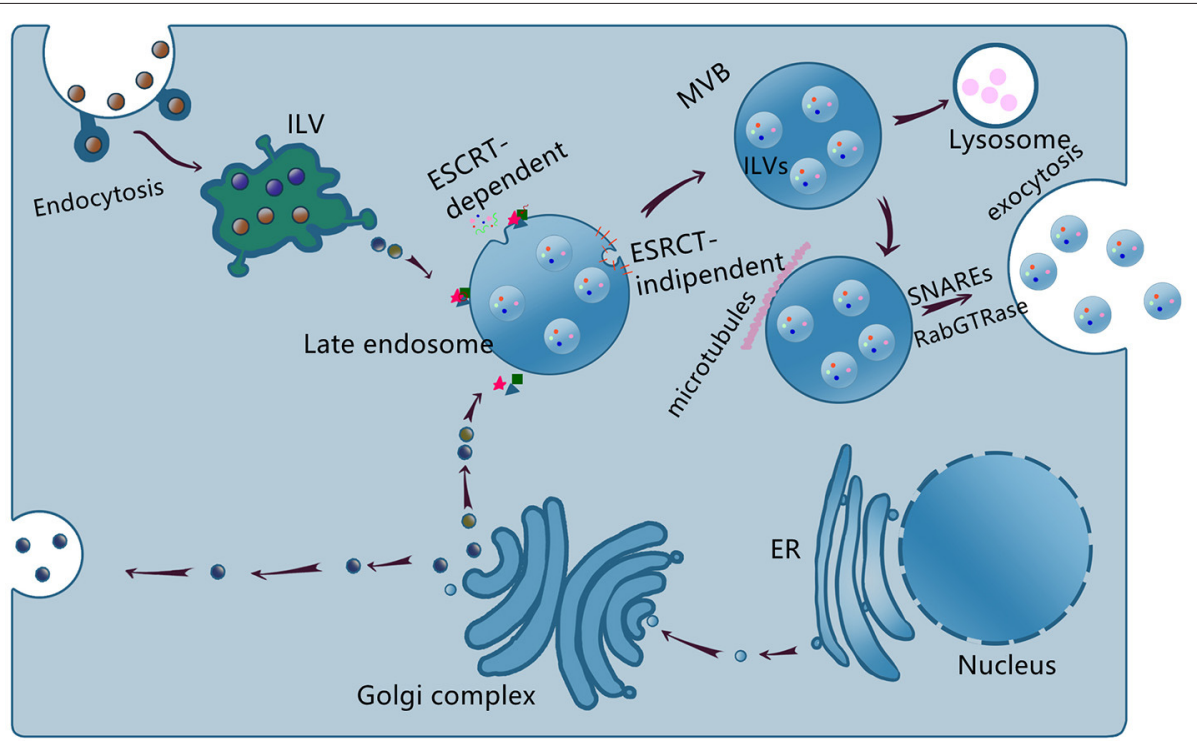

FIGURE 1 | Schematic representation of exosome biogenesis, sorting, and release. The endosome membrane invaginates and sprouts to form intraluminal vesicle (ILV), the early endosome, and then matures to form multivesicular body (MVB) via ESCRT-dependent and ESCRT-independent, the late endosome. Some MVBs reach lysosome and the contents are degraded, others transported to the cell membrane to release exosomes via SNAREs and RabGTPase. 
biologically active molecules, modulating the function and behavior of the recipient cells. There is compelling evidence of this process occurring in a variety of diseases including cardiovascular diseases $(11,18,20,27,32,33,41)$.

\section{Exosome Isolation}

The isolation of pure exosomes is a critical step to understand their structures and physio-pathological roles in diseases. Nevertheless, there are no currently reliable protocols to isolate absolute pure exosomes. Although several methods have been used to isolate exosomes, each approach exhibits advantages and disadvantages (Table 1).

\section{Ultracentrifugation}

Ultracentrifugation is the most commonly used method for exosome isolation. The process consists of a series of centrifugation cycles at different centrifugal forces and durations to separate exosomes from other components (42-45).

\section{Density Gradient Centrifugation}

Density gradient centrifugation exploits differences in vesicle size and density through discontinuous density gradient layers with progressively decreased density from the bottom to the top (46-48).

\section{Cushion Combined With Density Gradient Ultracentrifugation}

In this protocol, the exosomes are firstly concentrated using a $60 \%$ iodixanol cushion to recover a maximum number of exosomes with their property preserved. Then, the concentrated exosomes are separated through the density gradient ultracentrifugation to remove the non-exosomes contaminants (22).

\section{Size-Based Isolation Methods}

Size-based isolation methods use filters (ultrafiltration) or chromatography columns and merely depend on size or weight. Size exclusion chromatography (SEC) is also a size-based separation technique that uses a stationary phase consisting of resin particles of known porous size to isolate exosomes (49-51).

\section{Immune-Affinity Purification of Exosomes}

Exosome membranes contain large quantities of proteins. These proteins can be tagged by their specific corresponding antibodies to identify and isolate exosomes $(45,52-54)$.

\section{Polymer-Based Precipitation}

Precipitation methods are easy and fast approaches for isolating exosomes, which use commercial kits. The exosomes are precipitated by altering their solubility in the solution $(50,55)$.

\section{Microfluidics-Based Isolation Techniques}

Recently, microfluidics-based technologies have been introduced to identify and isolate exosomes. This technique exploits both physical and biochemical properties of exosomes, such as acoustic, electrophoretic, and electromagnetic characteristics $(56,57)$.

\section{Other Isolation Methods Using Commercial Kits}

An increasing number of commercial kits are presently available for exosome isolation. Girijesh et al. analyzed these commercial kits regarding yield, purity, and downstream applications. They determined that the isolation kit by Invitrogen could isolate more exosomes from the culture supernatant than the IZON gelfiltration chromatography kit, 101-Bio PureExo kit, and affinitybased MagCapure kit. However, exosomes extracted using the Invitrogen kit contained cytotoxic chemicals, which may inhibit cell growth (58).

\section{Exosome Characterization}

The characterization of exosomes has been a challenge due to their nano-scale size. So far, several techniques were employed for exosome characterization. The detail advantages, disadvantages and procedure are summarized in Table $2(12,59-71)$.

\section{MECHANISMS OF AF}

The mechanisms of the AF are complex and multi-factorial, and the pathophysiology includes three phases: initiation, maintenance, and progression $(3,72)$. Conceptually, these components link to the triggers and substrates. A trigger can act as an initiator, and the maintenance and progression generally require a substrate (73). Changes in substrate usually cause electrical and structural remodeling (74-76). In addition, a progression occurs over time from the trigger-driven disease, through the progress of atrial substrate, to the structural remodeling. These phases correspond to the clinical observation that about $5 \%$ of the patients with pAF progress to the persistent form each year, and 35-40\% of PsAF patients may develop permanent $\mathrm{AF}$ within $<1$ year $(77,78)$.

\section{Triggers for AF}

Three main mechanisms causing focal triggers are: enhanced atrial automaticity, early after-depolarization, and delayed after-depolarization $(77,79)$. In this regard, cellular calcium homeostasis may play an important role, which may cause heterogeneous electrophysiological properties, and then induce a vulnerable substrate formation $(72,74,79,80)$. These changes causing electrophysiological heterogeneity can result in initiation and sustenance of arrhythmia $(72,81)$.

\section{Substrate Changes for AF}

Many theories about electrical remodeling have been proposed, and their common pathophysiological notion is reentry or microreentry (6). In myocardial AF, altered electrical property causes a shortening of the refractory period or slower conduction and thereby provides an anatomical substrate for reentry (5). Moreover, the structural changes such as dilatation and fibrosis of the atrium also affect the conduction and then maintain the reentry circuits $(81,82)$. Further, the calcium current is reduced by the inactivation and downregulation of the gene expression of calcium channels, which may lead to a shortening of the action potential $(5,83,84)$. 
TABLE 1 | Current available exosomes isolation techniques.

\begin{tabular}{ll}
\hline Method & Pros \\
\hline Ultracentrifugation & (1) The most commonly \\
& used method \\
& (2) Suitable for large \\
sample capacity
\end{tabular}

Density gradient centrifugation

(1) Two step method

(2) Single step method

(1) Integrity

(2) Higher recovery yield

(3) Cushion combined with density gradient
Size-based isolation methods chromatography (SEC)]
Immune-affinity purification

Polymer-based precipitation ultracentrifugation
(1) High purity

(2) Structure and function integrity
Cons

(1) Time-consuming, costly instrumentation

(2) Un-efficiently (3) Loss of large amount and damage of exosomes

(4) Unsuitable for small amounts of samples or rare samples

(1) Low yield and time-consuming The sample is usually layered onto the top of the (2) Unsuitable for large amounts of sample

Procedure and application

It consists of a series of centrifugation cycles of different centrifugal force and duration to separate exosomes. Centrifugation is initially performed at a low speed, followed by ultracentrifugation at 100,000 to $120,000 \times \mathrm{g}$. the appropriate medium. It is suitable for sample such as urine, ascites, and supernatant culture medium

density gradient medium and subjected to an extended round of ultracentrifugation. The
(1) High purity

(2) Preservation properties

(1) Rapid

(2) No requiring centrifuge equipment
(1) High purity

(2) Highly efficient

(3) Maintaining exosomes specific morphology, biological activity, and molecular profiles

(1) Easy, does not require any specialized equipment

(2) High recovery rate

(3) It is scalable for large sample sizes
(1) Unsuitable for large amounts of sample

(1) Time-consuming
(1) Isolation of exosomes larger than the pore size of the matrix of the stationary phase used

(2) Low yield and the purified sample is diluted

(3) Significant hands-on time for column preparation, washing, and equilibration

(4) Manual collection of fractions may introduce operator-dependent variability

(1) Multiple steps in sample preparation, making the isolation prone to errors

2) $\mathrm{PH}$ value and salt concentration of the buffer might affect the biological activity of exosomes

(1) It contains lots of contaminating proteins

(2) Polymer present in the sample may interfere with the downstream analyses

Finally, the isolated exosomes are resuspended in vesicles travel through the gradient until they reach the point at which their density matches the one of the surrounding solution. The separated exosomes are then conveniently recovered by simple fraction collection. The process is suitable for scale analysis of exosomes

The conditioned medium containing exosomes was directly loaded on $30 \%$ sucrose gradient and centrifuged at $100,000 \times \mathrm{g}, 4^{\circ} \mathrm{C}$ for $90 \mathrm{~min}$ Firstly concentrated by using $60 \%$ iodixanol cushion to maximize exosomes recovery. Then, the concentrated exosomes are separated through density gradient ultracentrifugation to remove non-exosomes contaminates

It uses a stationary phase consisting of resin particles with known porous size. Similarly to density gradient centrifugation, SEC has been shown to allow reduction of contaminant proteins. The process is suitable for small scale analysis of exosomes

Magnetic beads are widely used in this method for capturing anti-CD9, anti-CD63, and anti-CD81 antibodies and isolating exosomes

The sample is mixed with water excluding polymers, that tie up water molecules and force less soluble components out of solution. Generally, the biological fluid is incubated with a precipitation solution and, after incubation, the precipitate containing exosomes is isolated by low speed centrifugation. It is scalable for large sample sizes

(1) Not suitable for large volume, Microfluidic devices exploit sample-bead lack of method validation interactions and subsequent separation of the beads. The sample is incubated with capture beads off-chip, and only downstream bead separation step takes place on-chip.

(2) Microfluidics based membrane filtration approach
(1) Highly efficient and low cost

(1) Not suitable for large volume, lack of method validation
Devices use the micro-fluidics based membrane filtration approach isolating exosomes by their size. 


\begin{tabular}{|c|c|c|c|}
\hline \multirow[t]{2}{*}{ Method } & \multirow[t]{2}{*}{ Pros } & \multirow[t]{2}{*}{ Cons } & Procedure and application \\
\hline & & & $\begin{array}{l}\text { (1) the first such device is a nanoporous } \\
\text { membrane with an adjustable pore size } \\
\text { that inserted in a microfluidic chip; } \\
\text { (2) a multiscale filtration device, which ciliated } \\
\text { nanowire-on-micropillar structure that traps } \\
\text { specifically sized liposomes (3) a type of } \\
\text { microfluidic device based on pillar-array that } \\
\text { can sort particles in a continuous flow through } \\
\text { nano-deterministic lateral displacement. }\end{array}$ \\
\hline Commercial kits & \multicolumn{3}{|c|}{$\begin{array}{l}\text { The Invitrogen isolation kit could isolate more and a broad size distribution of exosomes from } \\
\text { the culture supernatant than the iZON gel-filtration chromatography kit, 101Bio PureExo kit, } \\
\text { and affinity-based MagCapure kit. The quantity and quality of RNA isolated from exosomes } \\
\text { showed no significant differences among these isolation kits. However, exosomes extracted } \\
\text { using the Invitrogen kit appear to contain cytotoxic chemicals, which inhibit cell growth }\end{array}$} \\
\hline
\end{tabular}

TABLE 2 | Current exosomes characterization techniques.

\begin{tabular}{|c|c|c|c|}
\hline Method & Advantages & Disadvantages & $\begin{array}{l}\text { Detectable size } \\
\text { range }\end{array}$ \\
\hline TEM & $\begin{array}{l}\text { High resolution, discriminate exosomes from } \\
\text { other similar-size contaminants, } \\
\text { immunostaining }\end{array}$ & $\begin{array}{l}\text { Sample preparation may change the morphology of } \\
\text { exosomes, potential damage by electron beam }\end{array}$ & $>5 \mathrm{~nm}$ \\
\hline NTA & $\begin{array}{l}\text { Easy sample preparation, fast analysis, high } \\
\text { resolution, vesicles are directly observed }\end{array}$ & $\begin{array}{l}\text { Possible overlaying effect of larger vesicles, fail to distinguish } \\
\text { exosomes from other nano-contaminants }\end{array}$ & $50-1,000 \mathrm{~nm}$ \\
\hline AFM & $\begin{array}{l}\text { Minimal sample preparation without any } \\
\text { destructive procedure }\end{array}$ & $\begin{array}{l}\text { Scan speed, temperature and state of the tip may influent the } \\
\text { analysis }\end{array}$ & $>5 \mathrm{~nm}$ \\
\hline DLS & High resolution & Fail to distinguish exosomes from other nano-contaminants & $>5 \mathrm{~nm}$ \\
\hline FACS & Able to identify specific EV subpopulations & Low detection sensitivity for EV & $>300 \mathrm{~nm}$ \\
\hline SEM & High-resolution imaging & $\begin{array}{l}\text { Complex sample preparation } \\
\text { Requires fixation and drying }\end{array}$ & $>5 \mathrm{~nm}$ \\
\hline TRPS & Information about surface charge of vesicles & $\begin{array}{l}\text { Pores may be easily blocked by particles, generate a signal } \\
\text { higher than the background noise of the system }\end{array}$ & $>5 \mathrm{~nm}$ \\
\hline Exoview platform & Small volume, low purification biases & Expensive instrumentation, time consuming & $>5 \mathrm{~nm}$ \\
\hline Flow cytometry & Fast analysis & Relate low resolution & Not available \\
\hline
\end{tabular}

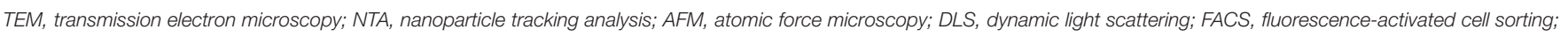
SEM, scanning electron microscopy; TRPS, tunable resistive pulse sensing.

\section{Atrial Fibrosis in AF}

Extensive evidence shows that structural remodeling, particularly interstitial fibrosis, critically contributes to the substrate formation for the AF (6). Angiotensin-II mediates cardiac fibrosis in a variety of cardiac pathologies (85-87). The angiotensin II induces the TGF- $\beta 1$ synthesis, which potently stimulates fibroblast activity. Moreover, the platelet-derived growth factor (PDGF) and connective tissue growth factor (CTGF) can also stimulate fibroblast proliferation and differentiation $(74,88-90)$.

\section{Atrial Apoptosis in AF}

All cellular lineages undergo programmed cell death, but the fibrillating atria are more prone to apoptotic activation (91). It is likely that the apoptotic process begins relatively early in the $\mathrm{AF}$ and causes tissue remodeling $(88,92)$. Evidence from experimental models suggests that apoptosis, leukocyte infiltration, and increased cell death occur early and precede the arrhythmogenic structural remodeling (93).

\section{Immune Response in AF}

The relationship between immune response and the AF is multiplex (94). Recently, several elucidations have shown that higher levels of inflammatory mediators and immune cells infiltration and are closely related to the AF (95). Inflammation could regulate calcium homeostasis and connexin expression, which in turn change the atrial substrates and cause AF initiation, and maintenance (96). The TNF not only could induce abnormal $\mathrm{Ca}^{2+}$ handling and arrhythmogenicity in pulmonary vein and cardiomyocytes, but also could activate the TGF- $\beta$ signaling pathway in the myofibroblasts and increase the matrix metalloproteinase (MMP)-2 and MMP-9 secretion (97). The IL-2 can change the amplitude of electrically stimulated and caffeineinduced $\mathrm{Ca}^{2+}$ transients in myocytes. Inflammation also could alter the atrial conduction properties and increase the conduction heterogeneity by affecting the expression or distribution of the gap junction protein connexin $(\mathrm{Cx})(\mathrm{Cx} 40$ and $\mathrm{Cx} 43)$, thereby inducing and maintaining AF (98). The leucocyte activation 
and increased levels of myeloperoxidase could increase the MMP-2 and MMP-9 activity, which then mediate atrial fibrosis and remodeling (99). Moreover, inflammatory mediators are associated with atrial electrical properties. The CD36 levels are positively correlated with the atrial voltage (100). Low levels of the HSP27 or CRP are associated with low atrial voltage (101).

\section{Atrial Myocardial Ischemia for AF}

Acute myocardial infarction (AMI) is often accompanied by AF (102). The incidence of new-onset AF among AMI events varied from 4.5 to $10.9 \%$ in clinical settings (103). The mechanism of new AF in AMI is multi-factorial, among which acute atrial ischemia (AAI) caused by AMI plays an important role (104). AMI would cause electrical instability of ventricular cardiomyocytes, causing ventricular tachycardia or ventricular fibrillation (105). Similarly, AAI can also easily cause electrical conduction disorders in atrial cardiomyocytes, thereby increasing the susceptibility to atrial fibrillation (106). Therefore, increasing the blood supply after AAI may have a positive effect on preventing and reducing the occurrence of atrial fibrillation in these patients.

\section{DIFFERENT EXPRESSION OF EXOSOME IN AF}

In the $\mathrm{AF}$, the cardiomyocytes and their microenvironment in the atria are in diverse pathological states. Because the biogenesis and secretion of exosomes significantly depend on the cellular conditions of the cardiomyocytes, the AF may cause changes in the exosomes profile and their cargoes in the atrial tissue and circulation (107).

Comparing the profile of circulating microparticles (MPs) between the AF patients and individuals with normal sinus rhythm (SR), Siwaponanan et al. found that the AF patients had significantly higher levels of cMPs (92). In addition, the EVs were measured in 836 patients with AF and in a cohort of control individuals in a study by Thulin et al. They showed that higher EVs were seen in anticoagulated patients with AF and a higher risk of stroke than the control population, possibly due to the high burden of AF (108). Moreover, Wang et al. found that the PsAF patients had a significantly increasing number of circulating microvesicles. Therefore, AF can cause different levels of circulating exosomes, especially PsAF (109).

Therefore, patients with AF have significant differentially expressed (DE)-exosomes, and the exosomes cargoes may be related to pro-inflammation, pro-fibrosis and apoptosis, which are important mechanisms of AF. Therefore, the exosomes may play a role in facilitating AF.

\section{CLINICAL AND BIOMEDICAL VALUES OF EXOSOME IN AF}

As stated previously, exosomes have been suggested as novel vehicles for intercellular communication in the cardiovascular system (71). Non-coding RNAs (ncRNAs) have emerged as important regulators of cardiac functions and diseases (110). So, the ncRNAs as important cargoes of exosomes, the exosomal ncRNAs (Exo-ncRNAs) should play an important role in the AF pathological process and can be used as diagnostic markers or in the treatment approach (111).

\section{NcRNAs in AF Progression}

NcRNAs mainly include miRNAs, long non-coding RNAs (lncRNAs) and circular RNAs ect. MiRNAs are small ncRNAs of 22-24 nucleotides that are capable of regulating gene expression by interacting with the mRNA transcript 3'UTRs and promoting mRNA degradation and/or protein translation blockage (112). LncRNAs are a more diverse group of ncRNAs, providing transcriptional and post-transcriptional roles and subclassified according to their functional properties (113). CircRNAs are a closed continuous loop, function as sponges for miRNAs to regulate the expression of target genes and directly regulate transcription with RNA Pol II or protein coding $(110,114)$. We summarized current state-of-the-art knowledge on the functional of ncRNAs and their regulatory mechanisms in AF.

\section{miRNAs in AF}

Many miRNAs are involved in cardiac remodeling, some of them regulate the ion channels, connexins or other proteins involved in the electrical remodeling, some regulate pro- or anti-fibrotic signaling cascades leading to the structural remodeling.

MiR-1 was down-regulated in the PsAF patients, accompanied by the up-regulation of KCNJ2 and IK1 density, which was associated with the shortening of the action potential duration (APD) and enabled the reentry and AF maintenance $(115,116)$. MiR-26 was also down-regulated in the fibrillating atria, causing an up-regulation of transient receptor potential cation 3 (TRPC3) channels, which regulated the calcium influx, cell proliferation, extracellular signal-regulated kinase phosphorylation in the cardiac fibroblasts $(117,118)$. Recently, down-regulation of miR-29b and miR-106b-25 cluster (miR-25, miR-93, and miR106b) was found in the AF patients atrial (119-121). MiR-30c and miR-133 down-regulation were accompanied by increased atrial fibrosis, and upregulation of their target gene CTGF, a pro-fibrotic mediator $(122,123)$. Besides, the MiR-133 was significantly down-regulated after the zinc finger homeobox 3 (ZFHX3) was knocked down, which increased the remodeling by targeted pro-fibrosis signaling (124). Additionally, up-/downregulation of miR-133/miR-590 resulted in down-/ up-regulation of their target gene TGF- $\beta 1 /$ TGF- $\beta$ R II collagen expression (125). MiR-21 was up-regulated in the cardiac fibroblasts, which aggravated the pro-fibrotic ERK-MAP kinase signaling pathway (126-128). MiR-328 was also up-regulated in the AF patients' atrial tissue. The over-expression of miR-328 could lead to L-type calcium current reduction and APD shortening, increasing the AF vulnerability $(129,130)$. MiR-499 was elevated in fibrillating atrial tissue. A relationship was found between the miR-499 and KCNN3, which may have been involved in the AF pathophysiology (131). Moreover, the miR-499 mediated the AF by altering the mitochondrial fission and apoptosis signaling (132). MiR-208 can target the gene GJA5 encoding the cardiac $\mathrm{Cx} 40$, and therefore mediate the pro-arrhythmogenic remodeling (133-136). 


\section{Long Non-coding RNAs in AF}

LncRNAs are involved in gene expression and cellular activity through a variety of mechanisms. Dysregulation of lncRNAs may be associated with cardiac diseases.

Based on competing endogenous RNAs' (ceRNAs) hypothesis, RP11-296O14.3 may participate in the AF pathological process (137). The lncRNA TCONS_00106987 was found increased in a rabbit AF model, which promoted the electrical remodeling by sponging miR-26 to regulate the KCNJ2 (138). The lncRNA MIAT/TCONS_00202959 had an increase/decrease in fibrillating atrial tissues. The MIAT may target the miR-133a-3p to regulate the atrial fibrosis, and TCONS_00202959 may elongate the atrial effective refractory period (AERP) to decrease the AF inducibility (139, 140). Xu et al. (141) found that the lncRNA NONHSAT040387 and NONHSAT098586 were the most DE-lncRNAs in the AF patient blood samples. In another study, 19 DE-lncRNAs were identified from the AF patient monocytes, and the lncRNA HNRNPU-AS1 was the highest positive correlated one. Further, GO and KEGG analyses showed that these DE-lncRNAs were mainly involved in the metabolic, biosynthetic, RNA binding, NF-kappa B, and cytokine-cytokine receptor interaction signaling pathways (142). Additionally, the lncRNA GAS5 was found downregulated in the AF patients, and the change of the GAS5 occurred prior to the left atrial enlargement. Moreover, the GAS5 was negatively correlated to the ALK5, which could enhance the AF progression (143, 144). Besides, the IncRNA VDAC2P2, PVT1, NEAT1, PCAT1, LICPAR, and NRON were increased in the AF patients, which were positively correlated with the collagen production and fibroblasts proliferation (145-151). However, the lncRNA LINC00472 and HOTAIR were downregulated. The LINC00472 could regulate the AF progression via modulating the miR24/JP2/RyR2 signaling pathway, and HOTAIR could function as a ceRNAs in the Cx43 expression by sponging MiR-613 (151-154). In addition, NRON could alleviate atrial fibrosis through the suppression of M1 macrophages, promoting the M2 macrophage polarization. The lncRNA TCONS_00075467 could modulate the electrical remodeling by sponging miR328 to regulate the CACNA1C expression (155). The lncRNA AK055347 may accelerate the AF pathogenesis by dysregulating the mitochondrial energy production via the regulation of Cyp450, ATP synthase, and MSS51 (156). Microarray and RNAs sequencing (RNA-seq) were employed in the lncRNAs analysis. The lncRNAs microarray of cardiac fibroblasts cells showed that the lncRNA AF159100, BC086588, and MRNR026574 were upregulated while the MRAK134679, NR024118, and AX765700 were down-regulated (157). Another analysis showed that the lncRNA ENST00000559960/ uc004aef.3 was up-regulated/downregulated in the AF patients' leukocytes (158). The RNAseq analysis of lncRNAs in the AF canine cardiac fat pads showed that the TCONS_00032546 and TCONS_00026102 could shorten the AERP and increase the AF inducibility (159). The RNA-seq analysis in the AF patients showed that several DElncRNAs were involved in the signaling pathways associated with the PI3K/Akt, TGF- $\beta$, calcium, inflammation, oxidative stress, autophagy, apoptosis, and collagen synthesis $(160,161)$. Moreover, another RNA-seq data by Ke et al. identified that the
lncRNA RP11-99E15.2 and RP3-523K23.2 participated in the AF pathogenesis via regulating the extracellular matrix binding and the transcription of the HSF2 (162).

\section{Circular RNAs in AF}

Recently, studies showed a potential role of circRNAs in myocardial fibrosis and thus initiation and progression of the AF.

The circRNA-miRNA networks showed extensive interaction among DE-circRNAs and the AF-related miRNAs and mRNAs (163). The circRNAs microarray found 120 DE-circRNAs in the AF patients' monocytes. The circRNA_7571, circRNA_4648, circRNA_4631, and circRNA_2875 had the most binding nodes in the circRNA-miRNA networks and were closely interacted with the miRNAs (142). In addition, Gao et al. found that in the PsAF blood samples, circ_0004104 promoted cardiac fibrosis via the TGF- $\beta$ pathway. Several other studies identified DE-circRNAs in the atrial tissues of AF patients (164). Zhang et al. identified 147 DE-circRNAs and GO and KEGG analyses indicated that many DE-circRNAs transcribed from the host genes were implicated in the regulation of sequencespecific DNA binding transcription factor activity (165). Zhang et al. (166) recognized 23 DE-circRNAs and circ_0000075 and_0082096 may participate in the AF pathogenesis via the TGF- $\beta$ pathway. Another RNA-seq analysis found 296 DEcircRNAs and the circRNA-associated with the ceRNAs network may induce the AF through the cardiac muscle contraction alterations. Simultaneously, these DE-circRNAs may be involved in regulating the miR-208b and miR-21 expression (167). Another RNA-seq analysis in the patients with the PAF and PsAF found an increase of circRNAs from PAF transition to PsAF, accompanied by miRNAs down-regulation (168). According to an analysis of DE-circRNAs and ceRNAs network in the AF patients from the GEO database, 376 DE-circRNAs were identified, which were enriched in the cytokine-cytokine receptor interaction, and two ceRNAs pairs were identified (circRNA100053- miR-455-5p-TRPV1 and circRNA-005843- miR-188-5pSPON1) $(169,170)$.

\section{Exosomal-NcRNAs in AF}

\section{Exo-NcRNAs as Pathogenic Factors for AF}

Many studies have found that exo-ncRNAs are related to the initiation and progression of Af. Myofibroblast-derived exo-miR-21-3p could reduce Cav1.2 expression, by regulating the AKAP/PKC signaling pathway, and then increase AF susceptibility $(87,171)$. Lu et al. found that exo-miR-328 could target the genes CACNA1C and CACNB1, which encode Ltype calcium channels, and then lead to atrial remodeling (172). Shan et al. (125) showed that, in canines atrial fibroblasts, the decreased expression of exo-miR-133 and miR-590 were associated with atrial fibrosis, and then promoted AF. Epicardial fat (eFat) contains amounts of exsomes rich in pro-inflammatory and pro-fibrotic molecules, which can affect the neighboring atria, and induce the initiation and maintenance of AF (173175). According to these researches, eFat tissues were collected from AF patients and were grown as organ cultures by ShaihovTeper. eFat-EVs were isolated from the culture medium for further analysis. Moreover, to establish a causal association 
between eFat-EVs and vulnerability to AF, the study generated an in vitro AF model using induced pluripotent stem cellderived cardiomyocytes (iCMs). The cultured explants from patients with AF secreted more EVs and harbored greater amounts of pro-inflammatory and pro-fibrotic cytokines, as well as pro-fibrotic miRNAs. Moreover, the eFat-EVs from patients with AF impacted the proliferation and migration of human mesenchymal stem cells (MSCs) and endothelial cells (ECs) and induced sustained reentry in iCMs (1). Some other studies also revealed that cardiomyocytes derived exo-miR-1, -miR-208a, miR-21, -miR-223, -miR-26, -miR-29b, -miR-328, and -miR-499 could target pathways which involved in myocardial metabolism and remodeling $(5,172,176)$. In short, these finding reveal the connection between exo-ncRNAs and the pathogenesis of AF, which may provide a promising alternative strategy to improving AF prevention and treatment.

\section{Exo-NcRNAs as Diagnostic Biomarkers for the AF}

Circulating miRNAs hold great promise as new diagnostic and prognostic biomarkers for cardiovascular diseases, but the specificity and sensitivity of the miRNAs could be affected by several factors. Due to the protection by the lipid bilayer membrane, circulating exo-miRNAs would provide stable miRNAs, and therefore, circulating exo-miRNAs may possess higher sensitivity and specificity to use as potential biomarkers for cardiovascular diseases (32). Nowadays, circulating exomiRNAs as biomarkers were mainly used in the AMI, CHF, and CAD (exo-miR-150, -miR-320a, and -miR-208b ect.) (121, 177). Some studies have also found circulating exo-miRNAs could be used as diagnostic/prognostic biomarkers for AF. A study comparing circulating the exo-miRNAs between the patients with SR, PAF, and PsAF.

Wei et al. identified significant three DE-exo-miRNAs (miR92b-3p, miR-1306-5p, and miRlet-7b-3p), and these miRNAs and target genes participated in $\mathrm{AF}$ pathogenesis, like as energy metabolism, lipid metabolism, inflammation, and enzyme activity (178). Wang et al. found that circulating exo-miRNAs: miR-483-5p, miR-142-5p, miR-223-3p were correlated with the $\mathrm{AF}$ and multivariate logistic analysis suggested that the miR483-5p was independently in correlation with the AF (179). A study by Mun et al. also found that compared with patients with supraventricular tachycardia, the expression level of 45 circulating exo-miRNAs in patients with perAF was significantly increased ( $>1.5$ times). What's more, the DE circulating exomiRNAs (miRNA-103a, miR-107, miR-320d, miR-486, and let$7 \mathrm{~b})$ were increased by more than 4.5 times in the PsAF. Moreover, these miRNAs and their target genes were involved in the atrial structure and function, oxidative stress, and fibrosis pathways (180). Further, Liu et al. isolated exosomes from pericardial fluid (PF), and found that the miR-382-3p, miR-450a-2-3p, and-3126-5p in the exosomes, and especially the miR-382-3p seemed pivotal in the AF progression (181). Therefore, circulating exo-miRNAs have the potential to serve as biomarkers in assessing the AF severity or prognosis, but more rigorous studies are necessary to confirm the supposition (Table 3).

\section{Exo-NcRNAs as Potential Therapeutics Approaches in Pathogenic Mechanism of AF}

There has been no research on the application of exosomes to the treatment of AF patients. Even in terms of animal experimental studies, direct data to prove the treatment of atrial fibrillation by exosomes-NCRNA is very limited. However, as mentioned previously, the mechanisms of the AF are closely linked to fibrosis, remodeling, inflammation, and apoptosis. In addition, acute atrial ischemia is always accompanied by AF. Therefore, the intervention on these mechanisms may provide a promising alternative new directions for AF treatment. Growing evidence suggests the role of exo-ncRNAs on these mechanisms, and therefore, the exo-ncRNAs may be used as the potential therapeutic tool for AF (18) (Table 3).

\section{Anti-fibrosis}

Adipose-derived stem cells (ADSCs)-exo-miR-146 could inhibit myocardial fibrosis by down-regulating the gene EGR1 (182). The exo-Let-7c originating from the MSCs exhibits antifibrotic property, through regulating the TGF- $\beta / S m a d$ (183). The exomiR-17 and miR-210 derived from the cardiac progenitor cells (CPCs) could inhibit the TGF- $\beta$-induced fibrosis under oxidative stress (184). Bone marrow-derived MSCs (BMMSCs)-exo-miR22 could target the Mecp2 to alleviate fibrosis (185). Moreover, exosomes enriched with the miR-290, miR-294, and miR-295 derived from the embryonic stem cells (ESCs) could significantly ameliorate fibrosis (186). Cardiomyocytes-exo-miR-378, miR29a, miR-29b, and miR-455 could exert an anti-fibrotic effect by reducing the collagen and MMP9 via inhibiting the MAPK and Smad pathways (187). Moreover, the exo-miR-320 derived from diabetic cardiomyocytes could negatively affect the proliferation and migration of ECs $(188,189)$. Furthermore, CD133+-exomiR-126 could reduce VCAM, SPRED-1, and MCP1, and subsequently decrease the interstitial fibrosis (190). Activated macrophage-exo-miR-155 has been shown to decrease fibroblast proliferation by inhibiting the SOS-1 (191). The miR-126, miR425, and miR-744 enriched exosomes could inhibit fibrosis by targeting the f TGF- $\beta$ and collagen I (192-194). Further, exomiR-26a could blunt the FOXO1 activation and inhibit cardiac fibrosis (195). However, several exo-miRNAs have controversial properties. The exo-miR-21 and miR-181b could reduce or accelerate cardiac fibrosis under different conditions $(196,197)$. In RHD, the exo-miR-155-5p could reduce valvular fibrosis by inhibiting the SOCS1/ STAT3 pathway (25, 198). Moreover, lncRNA Mhrt was shown to inhibit cardiac fibrosis and cardiac myocyte hypertrophy (199).

Aforementioned, atrial fibrosis plays an important in atrial remodeling. A variety of exo-ncRNAs, especially derived from stem cells, can inhibit and improve myocardial fibrosis through a variety of pathways. Therefore, we believe that the treatment based-on these exo-ncRNAs may be an important strategy to prevent and treat AF by inhibiting fibrosis.

\section{Anti-apoptosis}

The exo-miR-320d from the ADSCs negatively regulated STAT3 expression, indirectly inhibited cardiomyocytes apoptosis in AF, and increased survival, providing new insights into treatment 
TABLE 3 | EXo-ncRNAs as potential diagnostic biomarkers and therapeutics approaches in pathogenic mechanism of AF.

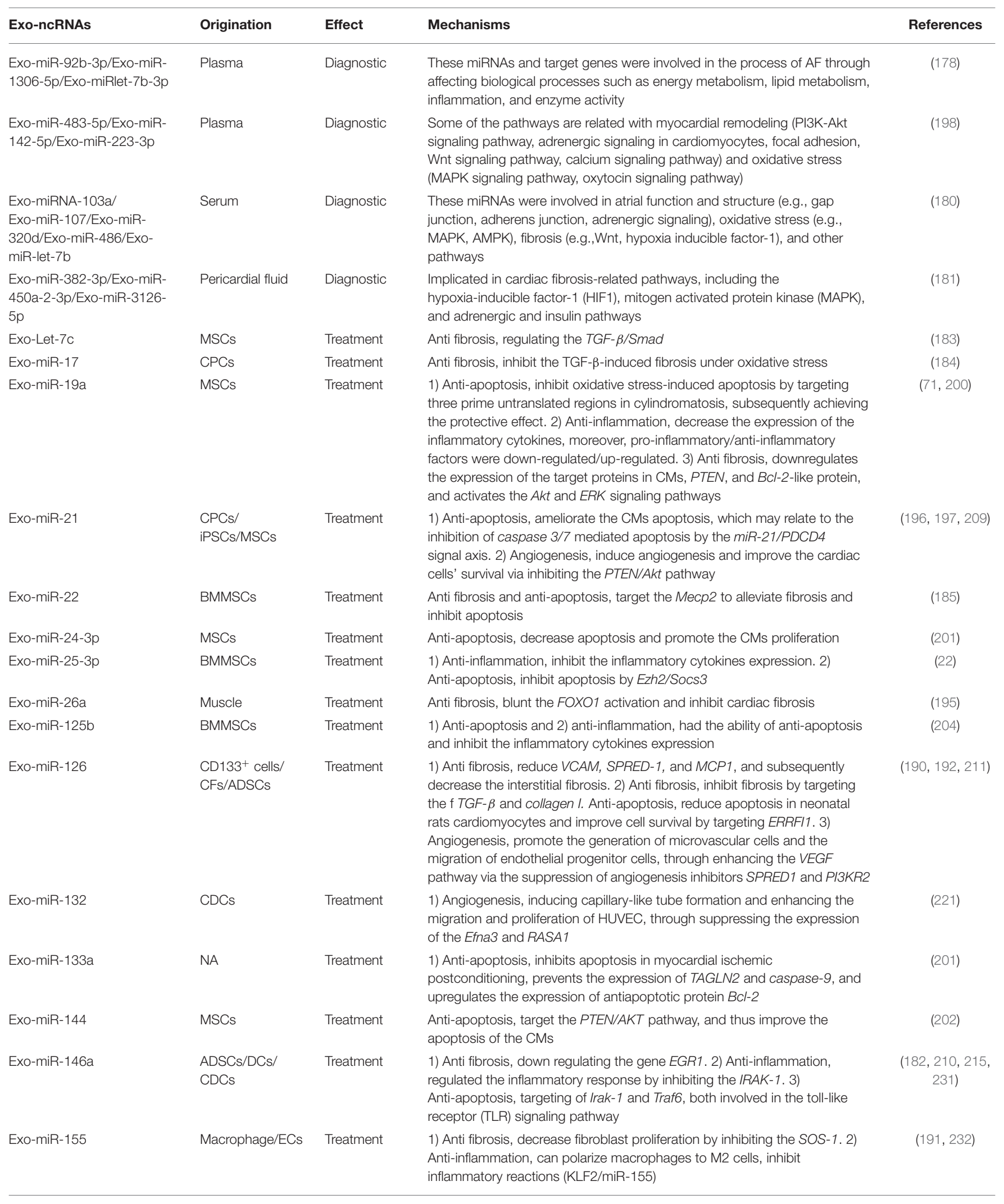


TABLE 3 | Continued

\begin{tabular}{|c|c|c|c|c|}
\hline Exo-ncRNAs & Origination & Effect & Mechanisms & References \\
\hline Exo-miR-155-5p & Serum & Treatment & $\begin{array}{l}\text { 1) Anti fibrosis, enhances the S1PR1 and inhibits the SOCS1/STAT3 } \\
\text { signaling pathway, thereby reducing the 2) Anti-inflammation, reduce the } \\
I L-6 \text { and IL-17 in the valve tissue and serum }\end{array}$ & $(214)$ \\
\hline Exo-miR-181a & MSCs & Treatment & $\begin{array}{l}\text { Anti-inflammation, create an anti-inflammatory environment and increase } \\
\text { the Tregs polarization }\end{array}$ & $(213)$ \\
\hline Exo-miR-185 & BMMSCs & Treatment & $\begin{array}{l}\text { Anti-apoptosis and anti-inflammation, had the ability of anti-apoptosis } \\
\text { targeting Socs } 2\end{array}$ & $(207)$ \\
\hline Exo-miR-210 & CPCs/MSCs & Treatment & $\begin{array}{l}\text { 1) Anti fibrosis, inhibit the TGF- } \beta \text {-induced fibrosis under oxidative stress. } \\
\text { 2) Anti-apoptosis, downregulated its known targets, ephrin A3 and PTP1b, } \\
\text { inhibiting apoptosis in cardiomyocytic cells. 3) Angiogenesis, inducing } \\
\text { capillary-like tube formation and enhancing the migration through } \\
\text { suppressing the expression of the Efna3 and RASA1 }\end{array}$ & $\begin{array}{c}(184,205,219, \\
220)\end{array}$ \\
\hline Exo-miR-221 & MSCs & Treatment & $\begin{array}{l}\text { Anti-apoptotic by inhibiting the } P 53 \text { and } B c l-2 b \text { and reducing the } \\
\text { methylation of } C p G \text { binding protein- } 2\end{array}$ & $(206)$ \\
\hline Exo-miR-223 & BMMSCs & Treatment & $\begin{array}{l}\text { Anti-inflammation, induce the expression of } I C A M-1 \text { to inhibit the } \\
\text { inflammatory reaction }\end{array}$ & $(218)$ \\
\hline Exo-miR-320 & CMs & Treatment & Anti fibrosis, negatively affect the proliferation and migration of ECs & $(188)$ \\
\hline Exo-miR-320d & ADSCs & Treatment & $\begin{array}{l}\text { Anti-apoptosis, negatively regulated STAT3 expression, indirectly inhibited } \\
\text { CMs apoptosis in AF, and increased survival, providing new insights into } \\
\text { treatment strategies of AF }\end{array}$ & $(17)$ \\
\hline Exo-miR-423-3p & CFs & Treatment & $\begin{array}{l}\text { Anti-apoptosis, improve the viability of the } \mathrm{H} 2 \mathrm{C} 9 \text { and reduce apoptosis by } \\
\text { targeting the RAP2C }\end{array}$ & $(212,213)$ \\
\hline $\begin{array}{l}\text { Exo-miR-290/Exo-miR- } \\
\text { 294/Exo-miR-295 }\end{array}$ & ESCs & Treatment & $\begin{array}{l}\text { Anti fibrosis, anti-apoptosis and angiogenesis, increases neovascularization } \\
\text { improves cardiomyocyte survival and reduces fibrosis. Enhances cardiac } \\
\text { progenitor cell survival and proliferation, as well as cardiac commitment }\end{array}$ & $(186)$ \\
\hline $\begin{array}{l}\text { Exo-miR-378/Exo-miR- } \\
29 a / E x o-m i R-29 b / E x o-m i R- \\
455\end{array}$ & CMs & Treatment & $\begin{array}{l}\text { Anti fibrosis, reducing the collagen and MMP9 via inhibiting the MAPK and } \\
\text { Smad pathways }\end{array}$ & $(187)$ \\
\hline Exo-miR-425/Exo-miR-744 & Serum & Treatment & Anti fibrosis, inhibit fibrosis by targeting the $\mathrm{f} T \mathrm{TGF}-\beta$ and collagen I & $(193,194)$ \\
\hline $\begin{array}{l}\text { Exo-miR-181b/Exo-miR- } \\
182\end{array}$ & CDCs/MSCs & Treatment & $\begin{array}{l}\text { Anti-inflammation, reduce } P K C \delta \text { transcription. Promoted the polarization of } \\
\text { M2 macrophages and thereby alleviated the inflammatory response }\end{array}$ & $(216,217)$ \\
\hline $\begin{array}{l}\text { Exo-miR-150-5p/Exo-miR- } \\
\text { 142-3p/Exo-Let-7d }\end{array}$ & Tregs & Treatment & $\begin{array}{l}\text { Anti-inflammation, reduce the immune reactions, and suppress the Th1 } \\
\text { proliferation and secretion of the pro-inflammatory cytokines }\end{array}$ & $(209,223)$ \\
\hline Exo-IncRNA Mhrt & ND & Treatment & Anti fibrosis, inhibit cardiac fibrosis and cardiac myocyte hypertrophy & $(199)$ \\
\hline
\end{tabular}

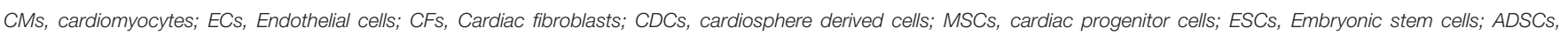
adipose-derived stem cells; BMMSCs, bone marrow derived cardiac progenitor cells; CPCs, cardiac progenitor cells; iPSCs, induced pluripotent stem cells. ND, Not Determined.

strategies of AF (17). The MSCs-exo-miR-19a could inhibit oxidative stress-induced apoptosis by targeting three prime untranslated regions in cylindromatosis (CYLD), subsequently achieving the protective effect $(11,200)$. Another exo-miRNA derived from the MSCs (exo-miR-24-3p) was also found to decrease apoptosis and promote the cardiomyocytes (CMs) proliferation (201). Under hypoxia, the MSCs-exo-miR-144 could target the PTEN/AKT pathway, and thus improve the apoptosis of the CMs (3, 202). Moreover, the exo-miR-210 and exo-miR-133a could inhibit apoptosis under hypoxia, by preventing transgelin 2 (TAGLN2) and caspase-9, and upregulating the anti-apoptotic protein $\mathrm{Bcl}-2 \mathrm{~b}$. Simultaneously, it improved the ability to resist oxidative stress and supported the stem cells' survival $(203,204)$. Exosome-derived miR210 downregulated its known targets, ephrin A3 and PTP1b, inhibiting apoptosis in cardiomyocytic cells (205). The BMMSCsexo-miR-22 to reduce the methylation of CpG binding protein-2 and reduce cardiomyocyte apoptosis (186), and BMMSCs-exo-miR-221 could mediate the anti-apoptotic effect by inhibiting the P53 and Bcl-2b (206). Moreover, the BMMSCsexo-miR-185 and exo-miR-125b had the ability of anti-apoptosis $(207,208)$. The exo-miR-21 originating from the CPCs and iPSCs was reported to ameliorate the CMs apoptosis, which may relate to the inhibition of caspase $3 / 7$ mediated apoptosis by the miR21/PDCD4 signal axis $(183,196,209)$. The CDCs-exo-miR-146a could reduce scar formation after myocardial infarction in rats, inhibit cardiomyocyte apoptosis, and improve heart function (210). In addition, Wang et al. showed that the exo-miR-126 could reduce apoptosis in neonatal rats cardiomyocytes and improve cell survival (211). Cardiac fibroblasts-exo-miR-423-3p was also found to improve the viability of the $\mathrm{H} 2 \mathrm{C} 9$ and reduce apoptosis by targeting the RAP2C (212).

Cardiomyocytes apoptosis can occur earlier than atrial remodeling. AF can also aggravate the apoptosis. Cardiomyocytes apoptosis and AF are a mutually deteriorating process. Early intervention for apoptosis may prevent and inhibit the initiation and progression of AF. Previous studies showed that exo-ncRNAs have important significance in improving apoptosis. Therefore, 
we believe that exo-ncRNAs with anti-apoptotic functions may have potential prospects in the treatment of AF.

\section{Anti-inflammation}

The MSCs-exo-miR-19a could decrease the expression of the inflammatory cytokines. In addition, the pro-inflammatory/antiinflammatory factors were down-regulated/up-regulated by the treatment with the exo-miR-19a (71). The MSCs-exo-miR-181a could create an anti-inflammatory environment and increase the Tregs polarization (213). Moreover, the exosomes derived from Tregs could transfer the miR-150-5p, miR-142-3p, and Let-7d to dendritic cells (DCs) and T-helper 1 (Th1), reduce the immune reactions, and suppress the Th1 proliferation and secretion of the pro-inflammatory cytokines (214). The exo-miR-146a secreted by the $\mathrm{DCs}$ regulated the inflammatory response by inhibiting the IRAK-1 (215). Further, the CDCs-exo-miR-181b and BMMSCsexo-miR-182 promoted the polarization of the $\mathrm{M} 2$ macrophages and thereby alleviated the inflammatory response $(216,217)$. The BMMSC-exo-miR-25, -miR-185, -miR-125b, and ADSCs-exomiR-126 were also found to inhibit the inflammatory cytokines expression (207). Moreover, the exo-miR-223 and miR-210 could induce the expression of ICAM-1 to inhibit the inflammatory reaction $(25,32,218)$.

The immune response participates in the pathogenesis of a variety of cardiovascular diseases, including AF. Antiinflammatory has been validated maybe useful for the treatment of AF. EXo-ncRNA, as a new strategy for anti-inflammatory, should have important significance in the treatment of AF, but more researcsh are still needed.

\section{Angiogenesis}

The ADSCs-exo-miR-126 was found to promote the generation of microvascular cells and the migration of endothelial progenitor cells, through enhancing the VEGF pathway via the suppression of angiogenesis inhibitors SPRED1 and PI3KR2 (192). The EMSCs-exo-miR-21 could induce angiogenesis and improve the cardiac cells' survival via inhibiting the PTEN/Akt pathway (197). The BMSCs-exo-miR-210 and miR-132 could promote angiogenesis, inducing capillary-like tube formation and enhancing the migration and proliferation of HUVEC, through suppressing the expression of the Efna3 and RASA1 (219-221). Moreover, several MSCs-exo-miRNAs including miR$30 \mathrm{~b}$, miR-30c, miR-424, and let-7 were identified to exert proangiogenic properties (178).

Promoting angiogenesis in ischemic areas is one of the important methods to improve MI. As previously stated, AAI can increase the susceptibility to AF, so promoting angiogenesis may be an important method for the treatment and prevention of AF. The exosomes-ncRNA may have an irreplaceable role in promoting angiogenesis.

\section{EXOSOME ENGINNERING FOR AF TREATMENT}

\section{Direct Exosome Engineering}

In direct encapsulation of cargoes into exosomes by sucrose gradient ultracentrifugation, Sun et al. used sucrose gradient ultracentrifugation successfully to encapsulate curcumin (a hydrophobic reagent) into the EL-4 cells-derived exosomes (222). However, this protocol can only be used for hydrophobic drugs. In order to address this, more active encapsulation techniques were applied, such as loading of catalase along with (1) incubation with and without saponin, (2) freeze-thaw cycles, (3) sonication and extrusion (223). Other processes like lipofection and electroporation have limited transfer efficiency and exosome concentration. As an alternative approach, the EVs-imitating structures were developed (173). Liposomes may be the most promising EV-imitating structure (224). Exosome delivery approaches mainly include intravenous injection or direct injection into the target area. Study found that injection of the liposomes into the infarct zone had significant antiinflammatory, anti-fibrotic, and pro-angiogenetic effects (223).

\section{Indirect Exosome Engineering}

Insufficient retainment in the myocardium is one of the major challenges in using exosomes for clinical applications. Currently, technologies for increasing exosomes retainment are being developed. Many targeting molecules have been developed for the exosome conjugation to enhance the retention and achieve the target delivery to the cardiac tissue. For example, AlvarezErviti et al. fused cardiomyocyte-specific binding peptide to the exosomal $\mathrm{N}$-terminus of murine transmembrane protein Lamp2b to improve the cardiac tropism of the exosomes (225). Vandergriff et al. designed the myocardium-targeting exosomes with cardiac homing peptide (CHP) and found increased cells viability and exosomal uptake in the cardiomyocytes (226). The other example of indirect engineering is the manipulation of the loading mechanism to selectively load cargoes into the exosomes. Moreover, an attractive tool for protein delivery by the exosomes, which was based on the integration of a reversible protein interaction module was sensitive to blue light and led to the protein loading into exosomes (227). In addition, through transferring encoding genes to the parent cells, exosomes with enhanced production efficiency, specific packaging ability, and the delivery to target cells were developed, which comprised of a production booster, an active packaging device, and a cytosolic delivery helper $(166,228)$. The latest advances in biomaterials such as heart patches and hydrogels have made them the new favorites for endogenous repair treatments. Liu et al. loaded the exo-miRNAs into hydrogels and exploited them in situ to the rat hearts. This approach made the more sustainable exosomes with higher bioavailability, improved cardiac functions, and decreased CMs apoptosis (229). Studies by Vunjak-Novakovic et al. and Chen et al. reported similar results (166). Moreover, encapsulating the exosomes with the antioxidant peptides could enhance exosome targeting effects. Nevertheless, the targeted exosome delivery approaches with enhanced retention still need to be further explored. Moreover, those delivery approaches can be incorporated with a minimally invasive surgical approach such as CT or ultrasound guide tube pericardiostomy to reduce the risk associated with the treatment (Table 4).

Overall, exosomes prepared by exosome engineering may have a wide spectrum of prospects for the treatment of diseases including AF. 
TABLE 4 | Current exosomes engineering techniques for Af treatments.

\begin{tabular}{|c|c|c|}
\hline Exosomes engineering technologies & Pros & Cons \\
\hline $\begin{array}{l}\text { Encapsulate cargoes by sucrose gradient } \\
\text { ultracentrifugation }\end{array}$ & $\begin{array}{l}\text { Protect drugs from degradation, enhance drugs stability, } \\
\text { bioavailability and effect }\end{array}$ & $\begin{array}{l}\text { This protocol can only be used for } \\
\text { hydrophobic drugs }\end{array}$ \\
\hline $\begin{array}{l}\text { Encapsulation cargoes through incubation, freeze-thaw } \\
\text { cycles, sonication, and extrusion }\end{array}$ & $\begin{array}{l}\text { Allows loading of both hydrophilic and hydrophobic } \\
\text { drugs }\end{array}$ & Causes exosomal bilayer disruption \\
\hline EV-imitating structure (liposomes) & Targeting, stable structure and contents & $\begin{array}{l}\text { Physiochemical instability } \\
\text { Can form unwanted degradants }\end{array}$ \\
\hline $\begin{array}{l}\text { Fusing cardiomyocyte-specific binding peptide to the } \\
\text { exosomes (Cardiac homing peptide) }\end{array}$ & Enhance exosomes targeting & Displays only protein loading \\
\hline $\begin{array}{l}\text { Manipulation of the loading mechanism to selectively } \\
\text { load cargoes into the exosomes (protein loading in } \\
\text { exosomes based on integration of light sensitive } \\
\text { reversible proteins interaction module) }\end{array}$ & $\begin{array}{l}\text { Enhance exosomes targeting } \\
\text { Controllable mechanism of loading }\end{array}$ & Displays only protein loading \\
\hline $\begin{array}{l}\text { Transfection of a gene encoding exosome-targeting } \\
\text { proteins into parent cells. }\end{array}$ & $\begin{array}{l}\text { Enhance production efficiency, specific packaging, and } \\
\text { delivery to target cells }\end{array}$ & Displays only protein loading \\
\hline Heart patches and hydrogels & $\begin{array}{l}\text { Making exosomes release more sustained with higher } \\
\text { bioavailability; enhance exosomes effects with better } \\
\text { target }\end{array}$ & $\begin{array}{l}\text { The delivery approaches with } \\
\text { enhanced retention is unsatisfactory }\end{array}$ \\
\hline
\end{tabular}

\section{ADVANTAGES AND DISADVANTAGES OF EXOSOME FOR AF}

Since the discovery of exosomes, studies on cardiovascular diseases (CVDs) have attracted extensive attention. In this review, we focused on the potential application of exosomes as diagnostic/prognostic and therapeutic tools in AF. Subsequently, we discussed the pros and cons of the use of exosomes. The application of exosomes has many advantages (32, 193, 230): (1) Alterations in exo-cargoes profile secreted by cardiac cells during AF would reflect the parental cells pathophysiological state with extreme specificity and sensitivity, and therefore they may appear as "fingerprint" of the AF pathogenetic processes; (2) Exosomes can be isolated from nearly all obtainable biofluids such as blood and urine; (3) Exosomes serve as a vehicle that protects cargoes from degradation and targets the cargoes to the recipient cells, with the less traumatic and abnormal modifications. (4) Welldesigned engineered exosomes may enhance their therapeutic effects, making them promising tools for clinical application. (5) Exosomes therapy has fewer ethical issues, compared with stem cell therapy. Although the exosomes application for the AF has significant benefits, it also has some limitations (31, 202, 228): (1) Exo-RNAs in the circulating come from different tissues, so the source of exosomes cannot be completely determined, which may affect the specificity of the biomarkers for diagnosing AF. (2) The extraction and purification of exosomes are very complicated without a gold standard, and the efficiency is limited, moreover, the specificity and contents of exosomes are unstable. (3) The safety and toxicity of exosomes cannot be fully established. Although lower immunogenicity was reported, some cases may suffer fever or allergic and hemolytic reactions ect. (4) The delivery methods of the exosomes to the heart are sub-optimal. Moreover, even many techniques have been applied to improve the exosome targeting, but there is still the possibility of "off-target," which may not only reduce efficiency but also cause additional side effects. (5) The dosage regimen of exosomes is not clear, and there are limitations on their pharmacokinetic parameters. (6) The exact exosomes' therapeutic effect is unclear, and how exosomes fulfill their specificity is yet to be fully understood.

Nowadays, exosomes have been extensively investigated in several pathological contexts such as ACS, MI, and HF diseases, but barely in the AF. However, as mentioned previously, as diagnostic biomarkers or treatment for AF, exosomes have many potential benefits, even if there are some limitations. Therefore, we need more elucidations to further clarify the exosomes' clinical value and side effects.

\section{CONCLUSION}

In the past decade, research on exosomes biology, pathophysiological function, and potential clinical application has increased exponentially and provided novel knowledge in mechanisms and cargoes of exosomes, thereby providing an opportunity to use in the AF diagnosis and treatment. The review of preclinical and clinical studies concluded that the circulating exosomes containing cardiac-specific cargoes, especially ncRNAs, have great potential for the AF diagnosis/prognosis. Further, exo-ncRNAs have important therapeutic effects on AF pathogenesis. Exosome engineering can improve the distribution and selectivity to control the exosomal cargoes. Encapsulation technology has generated a platform for the effective delivery of synthetic and biopharmaceuticals. Therefore, the application of the exo-ncRNAs in the AF may have a good prospect. However, the exo-ncRNAs research related to the AF is still in its infancy, and many aspects need to be improved: (1) The isolation, characterization, and identification should be standardized and simplified. (2) Nomenclature should be consistent. (3) Exosomes should be quantified. (4) Further elaboration on the exosomes mechanism, improvement of targeting, reducing degradation, increasing retention needs to be elucidated in future research. 
In conclusion, this review summarized the current biogenesis, isolation, biological functions, and future applications of the exosomes relevant to AF. Exosomes hold unprecedented opportunities for future applications for the AF either as biomarkers for diagnosis/prognosis or as therapeutic tools. Simultaneously, the challenges in the exosomes' application are also significant. Therefore, more prospective, large-scale, and multi-centered trials are needed before the exosomes can be used clinically in the AF. Undoubtedly, exosome-based application will herald a new chapter in clinical diagnosis/prognosis and treatment of AF.

\section{REFERENCES}

1. Shaihov-Teper O, Ram E, Ballan N, Brzezinski RY, NaftaliShani N, Masoud R, et al. Extracellular vesicles from epicardial fat facilitate atrial fibrillation. Circulation. (2021) 143:2475-93. doi: 10.1161/CIRCULATIONAHA.120.052009

2. Kornej J, Börschel CS, Benjamin EJ, Schnabel RB. Epidemiology of atrial fibrillation in the 21st century: novel methods and new insights. Circ Res. (2020) 127:4-20. doi: 10.1161/CIRCRESAHA.120.316340

3. Wijesurendra RS, Casadei B. Mechanisms of atrial fibrillation. Heart. (2019) 105:1860-7. doi: 10.1136/heartjnl-2018-314267

4. Krijthe BP, Kunst A, Benjamin EJ, Lip GY, Franco OH, Hofman A, et al. Projections on the number of individuals with atrial fibrillation in the European Union, from 2000 to 2060. Eur Heart J. (2013) 34:2746-51. doi: 10.1093/eurheartj/eht280

5. Clauss S, Sinner MF, Kääb S, Wakili R. The role of MicroRNAs in antiarrhythmic therapy f or atrial fibrillation. Arrhythm Electrophysiol Rev. (2015) 4:146-55. doi: 10.15420/aer.2015.4.3.146

6. Ng FS, Handa BS, Li X, Peters NS. Toward mechanism-directed electrophenotype-based treatments for atrial fibrillation. Front Physiol. (2020) 11:987. doi: 10.3389/fphys.2020.00987

7. Hlips T, Taghji P, El Haddad M, Wolf M, Knecht S, Vandekerckhove Y, et al. Improving procedural and one-year outcome after contact force-guided pulmonary vein isolation: the role of interlesion distance, ablation index, and contact force variability in the 'CLOSE'-protocol. Europace. (2018) 20:f419-27. doi: 10.1093/europace/eux376

8. van der Pol E, Boing AN, Harrison P, Sturk A, Nieuwland R. Classification, functions, and clinical relevance of extracellular vesicles. Pharmacol Rev. (2012) 64:676-705. doi: 10.1124/pr.112.005983

9. Røsand $\varnothing$, Høydal MA. Cardiac exosomes in ischemic heart disease-a narrative review. Diagnostics. (2021) 11:269. doi: 10.3390/diagnostics11020269

10. Slomka A, Urban SK, Lukacs-Kornek V, Zekanowska E, Kornek M. Large extracellular vesicles: have we found the holy grail of inflammation? Front Immunol. (2018) 9:2723. doi: 10.3389/fimmu.2018.02723

11. Liu Q, Piao H, Wang Y, Zheng D, Wang W. Circulating exosomes in cardiovascular disease: novel carriers of biological information. Biomed Pharmacother. (2021) 135:111148. doi: 10.1016/j.biopha.2020.111148

12. Zhang J, Cui X, Guo J, Cao C, Zhang Z, Wang B, et al. Small but significant: insights and new perspectives of exosomes in cardiovascular disease. J Cell Mol Med. (2020) 24:8291-303. doi: 10.1111/jcmm.15492

13. Wiklander OPB, Brennan MÁ, Lötvall J, Breakefield XO, El Andaloussi S. Advances in therapeutic applications of extracellular vesicles. Sci Transl Med. (2019) 11:eaav8521. doi: 10.1126/scitranslmed.aav8521

14. Wolf $\mathrm{P}$. The nature and significance of platelet products in human plasma. Br J Haematol. (1967) 13:269-88. doi: 10.1111/j.1365-2141

15. Johnstone RM, Adam M, Hammond JR, Orr L, Turbide C. Vesicle formation during reticulocyte maturation. Association of plasma membrane activities with released vesicles (exosomes). J Biol Chem. (1987) 262:9412-20.

16. Zamani P, Fereydouni N, Butler AE, Navashenaq JG, Sahebkar A. The therapeutic and diagnostic role of exosomes in cardiovascular diseases. Trends Cardiovasc Med. (2019) 29:313-23. doi: 10.1016/j.tcm.2018.10.010

\section{AUTHOR CONTRIBUTIONS}

CC and WZ researched the article and wrote the manuscript. QC, TZ, YP, YL, and YX reviewed and edited the manuscript before submission. All authors provided substantial contribution to the discussion of content.

\section{FUNDING}

This work was supported by Shanghai Science and Technology Commission, Grant No. 17DZ1930303.

17. Liu L, Zhang H, Mao H, Li X, Hu Y. Exosomal miR-320d derived from adipose tissue-derived MSCs inhibits apoptosis in cardiomyocytes with atrial fibrillation (AF). Artif Cells Nanomed Biotechnol. (2019) 47:3976-84. doi: 10.1080/21691401.2019.1671432

18. Xue R, Tan W, Wu Y, Dong B, Xie Z, Huang P, et al. Role of exosomal miRNAs in Heart Failure. Front Cardiovasc Med. (2010) 7:592412. doi: 10.3389/fcvm.2020.592412.19

19. Kowal J, Tkach M, Théry C. Biogenesis and secretion of exosomes. Curr Opin Cell Biol. (2014) 29:116-25. doi: 10.1016/j.ceb.2014.05.004

20. Henning RJ. Cardiovascular exosomes and microRNAs in cardiovascular physiology and pathophysiology. J Cardiovasc Transl Res. (2020) 14:195-212. doi: 10.1007/s12265-020-10040-5

21. Kalluri R, LeBleu VS. The biology, function, and biomedical applications of exosomes. Science. (2020) 367:eaau6977. doi: 10.1126/science.aau6977

22. Xiong YY, Gong ZT, Tang RJ, Yang YJ. The pivotal roles of exosomes derived from endogenous immune cells and exogenous stem cells in myocardial repair after acute myocardial infarction. Theranostics. (2021) 11:1046-58. doi: 10.7150/thno. 53326

23. Simons M, Raposo G. Exosomes-vesicular carriers for intercellular communication. Curr Opin Cell Biol. (2009) 21:575-81. doi: 10.1016/j.ceb.2009.03.007

24. Cheng M, Yang J, Zhao X, Zhang E, Zeng Q, Yu Y, et al. Circulating myocardial microRNAs from infarcted hearts are carried in exosomes and mobilise bone marrow progenitor cells. Nat Commun. (2019) 10:959. doi: 10.1038/s41467-019-08895-7

25. Zheng D, Huo M, Li B, Wang W, Piao H, Wang Y, et al. The role of exosomes and exosomal microRNA in cardiovascular disease. Front Cell Dev Biol. (2021) 8:616161. doi: 10.3389/fcell.2020.616161

26. Sahoo S, Losordo DW. Exosomes and cardiac repair after myocardial infarction. Circ Res. (2014) 114:333-44. doi: 10.1161/CIRCRESAHA.114.300639

27. McMahon HT, Boucrot E. Membrane curvature at a glance. J Cell Sci. (2015) 128:1065-70. doi: 10.1242/jcs.114454

28. Subra C, Grand D, Laulagnier K, Stella A, Lambeau G, Paillasse M, et al. Exosomes account for vesicle-mediated transcellular transport of activatable phospholipases and prostaglandins. J Lipid Res. (2010) 51:210520. doi: 10.1194/jlr.M003657

29. Jahn R, Scheller RH. SNAREs-engines for membrane fusion. Nat Rev Mol Cell Biol. (2006) 7:631-43. doi: 10.1038/nrm2002

30. Yoshioka Y, Konishi Y, Kosaka N, Katsuda T, Kato T, Ochiya T. Comparative marker analysis of extracellular vesicles in different human cancer types. $J$ Extracell Vesicles. (2013) 2:20424. doi: 10.3402/jev.v2i0.20424

31. Mancuso T, Barone A, Salatino A, Molinaro C, Marino F, Scalise M, et al. Unravelling the biology of adult cardiac stem cell-derived exosomes to foster endogenous cardiac regeneration and repair. Int J Mol Sci. (2020) 21:3725. doi: 10.3390/ijms21103725

32. Zhou R, Wang L, Zhao G, Chen D, Song X, Momtazi-Borojeni AA, et al. Circulating exosomal microRNAs as emerging non-invasive clinical biomarkers in heart failure: mega bio-roles of a nano bio-particle. IUBMB Life. (2020) 72:2546-62. doi: 10.1002/Iub.2396

33. Mathieu M, Martin-Jaular L, Lavieu G, Théry C. Specificities of secretion and uptake of exosomes and other extracellular vesicles 
for cell-to-cell communication. Nat Cell Biol. (2019) 21:9-17. doi: 10.1038/s41556-018-0250-9

34. Kamerkar S, LeBleu VS, Sugimoto H, Yang S, Ruivo CF, Melo SA, et al. Exosomes facilitate therapeutic targeting of oncogenic KRAS in pancreatic cancer. Nature. (2017) 546:498-503. doi: 10.1038/nature 22341

35. Nanbo A, Kawanishi E, Yoshida R, Yoshiyama H. Exosomes derived from Epstein-Barr virus-infected cells are internalized via Caveola-dependent endocytosis and promote phenotypic modulation in target cells. J Virol. (2013) 87:10334-47. doi: 10.1128/JVI.01310-13

36. Conner SD, Schmid SL. Regulated portals of entry into the cell. Nature. (2003) 422:37-44. doi: 10.1038/nature01451

37. Mulcahy LA, Pink RC, Carter DR. Routes and mechanisms of extracellular vesicle uptake. J Extracell Vesicles. (2014) 3. doi: 10.3402/jev.v3.24641

38. Parolini I, Federici C, Raggi C, Lugini L, Palleschi S, De Milito A, et al. Microenvironmental $\mathrm{pH}$ is a key factor for exosome traffic in tumor cells. J Biol Chem. (2009) 284:34211-22. doi: 10.1074/jbc.M109.041152

39. Saman S, Kim W, Raya M, Visnick Y, Miro S, Saman S, et al. Exosome-associated tau is secreted in tauopathy models and is selectively phosphorylated in cerebrospinal fluid in early Alzheimer disease. J Biol Chem. (2012) 287:3842-9. doi: 10.1074/jbc.M111.277061

40. Segura E, Guérin C, Hogg N, Amigorena S, Théry C. CD8+ dendritic cells use LFA-1 to capture MHC-peptide complexes from exosomes in vivo. $J$ Immunol. (2007) 179:1489-96. doi: 10.4049/jimmunol.179.3.1489

41. Colombo M, Raposo G, Théry C. Biogenesis, secretion, and intercellular interactions of exosomes and other extracellular vesicles. Annu Rev Cell Dev Biol. (2014) 30:255-89. doi: 10.1146/annurev-cellbio-101512-122326

42. Yamashita T, Takahashi Y, Nishikawa M, Takakura Y. Effect of exosome isolation methods on physicochemical properties of exosomes and clearance of exosomes from the blood circulation. Eur J Pharm Biopharm. (2016) 98:1-8. doi: 10.1016/j.ejpb.2015.10.017

43. Witwer KW, Buzás EI, Bemis LT, Bora A, Lässer C, Lötvall J, et al. Standardization of sample collection, isolation and analysis methods in extracellular vesicle research. J Extracell Vesicles. (2013) 27:2. doi: $10.3402 /$ jev.v2i0.20360

44. Jeppesen DK, Hvam ML, Primdahl-Bengtson B, Boysen AT, Whitehead B, Dyrskjøt L, et al. Comparative analysis of discrete exosome fractions obtained by differential centrifugation. J Extracell Vesicles. (2014) 3:25011. doi: 10.3402/jev.v3.25011

45. Li P, Kaslan M, Lee SH, Yao J, Gao Z. Progress in exosome isolation techniques. Theranostics. (2017) 7:789-804. doi: 10.7150/thno.18133

46. Onódi Z, Pelyhe C, Terézia Nagy C, Brenner GB, Almási L, Kittel Á, et al. Isolation of high-purity extracellular vesicles by the combination of iodixanol density gradient ultracentrifugation and bind-elute chromatography from blood plasma. Front Physiol. (2018) 9:1479. doi: 10.3389/fphys.2018.01479

47. Van Deun J, Mestdagh P, Sormunen R, Cocquyt V, Vermaelen K, Vandesompele J, et al. The impact of disparate isolation methods for extracellular vesicles on downstream RNA profiling. J Extracell Vesicles. (2014) 18:3. doi: 10.3402/jev.v3.24858

48. Smyth T, Kullberg M, Malik N, Smith-Jones P, Graner MW, Anchordoquy TJ. Biodistribution and delivery efficiency of unmodified tumor-derived exosomes. J Control Release. (2015) 199:145-55. doi: 10.1016/j.jconrel.2014.12.013

49. Hong CS, Funk S, Muller L, Boyiadzis M, Whiteside TL. Isolation of biologically active and morphologically intact exosomes from plasma of patients with cancer. J Extracell Vesicles. (2016) 5:29289. doi: 10.3402/jev.v5.29289

50. Lobb RJ, Becker M, Wen SW, Wong CS, Wiegmans AP, Leimgruber A, et al. Optimized exosome isolation protocol for cell culture supernatant and human plasma. J Extracell Vesicles. (2015) 4:27031. doi: 10.3402/jev.v4. 27031

51. Welton JL, Webber JP, Botos LA, Jones M, Clayton A. Ready-made chromatography columns for extracellular vesicle isolation from plasma. $J$ Extracell Vesicles. (2015) 4:27269. doi: 10.3402/jev.v4.27269

52. Zarovni N, Corrado A, Guazzi P, Zocco D, Lari E, Radano G, et al. Integrated isolation and quantitative analysis of exosome shuttled proteins and nucleic acids using immunocapture approaches. Methods. (2015) 87:4658. doi: 10.1016/j.ymeth.2015.05.028
53. Sharma P, Ludwig S, Muller L, Hong CS, Kirkwood JM, Ferrone S, et al. Immunoaffinity-based isolation of melanoma cell-derived exosomes from plasma of patients with melanoma. J Extracell Vesicles. (2018) 7:1435138. doi: $10.1080 / 20013078.2018 .1435138$

54. Grasso L, Wyss R, Weidenauer L, Thampi A, Demurtas D, Prudent $\mathrm{M}$, et al. Molecular screening of cancer-derived exosomes by surface plasmon resonance spectroscopy. Anal Bioanal Chem. (2015) 407:5425-32. doi: 10.1007/s00216-015-8711-5

55. Mathivanan S, Lim JW, Tauro BJ, Ji H, Moritz RL, Simpson RJ. Proteomics analysis of A33 immunoaffinitypurified exosomes released from the human colon tumor cell line LIM1215 reveals a tissue-specific protein signature. Mol Cell Proteomics. (2010) 9:197-208. doi: 10.1074/mcp.M900152-MCP200

56. Zhang $\mathrm{P}$, Zhou $\mathrm{X}$, He M, Shang Y, Tetlow AL, Godwin AK, et al. Ultrasensitive detection of circulating exosomes with a 3Dnanopatterned microfluidic chip. Nat Biomed Eng. (2019) 3:438-51. doi: 10.1038/s41551-019-0356-9

57. Guo SC, Tao SC, Dawn H. Microfluidics-based on-a-chip systems for isolating and analysing extracellular vesicles. J Extracell Vesicles. (2018) 7:1508271. doi: 10.1080/20013078

58. Patel GK, Khan MA, Zubair H, Srivastava SK, Khushman M, Singh S, et al. Comparative analysis of exosome isolation methods using culture supernatant for optimum yield, purity and downstream applications. Sci Rep. (2019) 9:5335. doi: 10.1038/s41598-019-41800-2

59. Théry C, Ostrowski M, Segura E. Membrane vesicles as conveyors of immune responses. Nat Rev Immunol. (2009) 9:581-93. doi: 10.1038/nri2567

60. Fevrier B, Raposo G. Exosomes: endosomal-derived vesicles shipping extracellular messages. Curr Opin Cell Biol. (2004) 16:415-21. doi: 10.1016/j.ceb.2004.06.003

61. Hartjes TA, Mytnyk S, Jenster GW, van Steijn V, van Royen ME. Extracellular vesicle quantification and characterization: common methods and emerging approaches. Bioengineering. (2019) 6:7. doi: 10.3390/bioengineerring6010007

62. Raposo G, Stoorvogel W. Extracellular vesicles: exosomes, microvesicles, and friends. J Cell Biol. (2013) 200:373-83. doi: 10.1083/jcb.201211138

63. Zaborowski MP, Balaj L, Breakefield XO, Lai CP. Extracellular vesicles: composition, biological relevance, and methods of study. Bioscience. (2015) 65:783-97. doi: 10.1093/biosci/biv084

64. Meng W, He C, Hao Y, Wang L, Li L, Zhu G. Prospects and challenges of extracellular vesicle-based drug delivery system: considering cell source. Drug Deliv. (2020) 27:585-98. doi: 10.1080/10717544.2020

65. Dragovic RA, Gardiner C, Brooks AS, Tannetta DS, Ferguson DJ, Hole P, et al. Sizing and phenotyping of cellular vesicles using nanoparticle tracking analysis. Nanomedicine. (2011) 7:780-8. doi: 10.1016/j.nano.2011.04.003

66. McNicholas K, Michael MZ. Immuno-characterization of exosomes using nanoparticle tracking analysis. Methods Mol Biol. (2017) 1545:35-42. doi: 10.1007/978-1-4939-6728-5_3

67. Sharma S, Rasool HI, Palanisamy V, Mathisen C, Schmidt M, Wong DT, et al. Structural-mechanical characterization of nanoparticle exosomes in human saliva, using correlative AFM, FESEM, and force spectroscopy. ACS Nano. (2010) 4:1921-6. doi: 10.1021/nn901824n

68. Allison DP, Mortensen NP, Sullivan CJ, Doktycz MJ. Atomic force microscopy of biological samples. Wiley Interdiscip Rev Nanomed Nanobiotechnol. (2010) 2:618-34. doi: 10.1002/wnan.104

69. Tatischeff I, Larquet E, Falcón-Pérez JM, Turpin PY, Kruglik SG. Fast characterisation of cell-derived extracellular vesicles by nanoparticles tracking analysis, cryo-electron microscopy, and Raman tweezers microspectroscopy. J Extracell Vesicles. (2012) 21:1. doi: 10.3402/jev.vli0.19179

70. van der Pol E, Coumans F, Varga Z, Krumrey M, Nieuwland R. Innovation in detection of microparticles and exosomes. J Thromb Haemost. (2013) 11(Suppl. 1):36-45. doi: 10.1111/jth.12254

71. Liu Y, Wang M, Liang Y, Wang C, Naruse K, Takahashi K. Treatment of oxidative stress with exosomes in myocardial ischemia. Int J Mol Sci. (2021) 22:1729. doi: 10.3390/ijms22041729

72. Heijman J, Voigt N, Nattel S, Dobrev D. Cellular and molecular electrophysiology of atrial fibrillation initiation, maintenance, and progression. Circ Res. (2014) 114:1483-99. doi: 10.1161/CIRCRESAHA.114.302226 
73. Haïssaguerre M, Jaïs P, Shah DC, Takahashi A, Hocini M, Quiniou G. Spontaneous initiation of atrial fibrillation by ectopic beats originating in the pulmonary veins. N Engl J Med. (1998) 339:659-66. doi: 10.1056/NEJM199809033391003

74. Nattel S, Burstein B, Dobrev D. Atrial remodeling and atrial fibrillation: mechanisms and implications. Circ Arrhythm Electrophysiol. (2008) 1:62-73. doi: 10.1161/CIRCEP.107.754564

75. Iwasaki YK, Nishida K, Kato T, Nattel S. Atrial fibrillation pathophysiology: implications for management. Circulation. (2011) 124:2264-74. doi: 10.1161/CIRCULATIONAHA.111.019893

76. Corradi D. Atrial fibrillation from the pathologist's perspective. Cardiovasc Pathol. (2014) 23:71-84. doi: 10.1016/j.carpath.2013.12.001

77. Nattel S, Guasch E, Savelieva I, Cosio FG, Valverde I, Halperin JL, et al. Early management of atrial fibrillation to prevent cardiovascular complications. Eur Heart J. (2014) 35:1448-56. doi: 10.1093/eurheartj/ ehu028

78. Camm AJ, Al-Khatib SM, Calkins H, Halperin JL, Kirchhof P, Lip GY, et al. A proposal for new clinical concepts in the management of atrial fibrillation. Am Heart J. (2012) 164:292-302. doi: 10.1016/j.ahj.2012.05.017

79. Wakili R, Voigt N, Kääb S, Dobrev D, Nattel S. Recent advances in the molecular pathophysiology of atrial fibrillation. J Clin Invest. (2011) 121:2955-68. doi: 10.1172/JCI46315

80. Savelieva I, Kakouros N, Kourliouros A, Camm AJ. Upstream therapies for management of atrial fibrillation: review of clinical evidence and implications for European Society of Cardiology guidelines. Part I: primary prevention. Europace. (2011) 3:308-28. doi: 10.1093/europace/eur002

81. Lozito TP, Tuan RS. Endothelial cell microparticles act as centers of matrix metalloproteinsase-2 (MMP-2) activation and vascular matrix remodeling. $J$ Cell Physiol. (2012) 27:534-49. doi: 10.1002/jcp.22744

82. Jalife J, Kaur K. Atrial remodeling, fibrosis, and atrial fibrillation. Trends Cardiovasc Med. (2015) 25:475-84. doi: 10.1016/j.tcm.2014.12.015

83. Chaumont C, Suffee N, Gandjbakhch E, Balse E, Anselme F, Hatem SN. Epicardial origin of cardiac arrhythmias: clinical evidences and pathophysiology. Cardiovasc Res. (2021). doi: 10.1093/cvr/cvab213. [Epub ahead of print].

84. Allessie MA, Boyden PA, Camm AJ, Kléber AG, Lab MJ, Legato MJ, et al. Pathophysiology and prevention of atrial fibrillation. Circulation. (2001) 103:769-77. doi: 10.1161/01.cir.103.5.769

85. Zhan Y, Abe I, Nakagawa M, Ishii Y, Kira S, Miyoshi M, et al. A traditional herbal medicine rikkunshito prevents angiotensin II-Induced atrial fibrosis and fibrillation. J Cardiol. (2020) 76:626-35. doi: 10.1016/j.jjcc.2020.07.001

86. Bi HL, Zhang YL, Yang J, Shu Q, Yang XL, Yan X, et al. Inhibition of UCHL1 by LDN-57444 attenuates Ang II-Induced atrial fibrillation in mice. Hypertens Res. (2020) 43:168-77. doi: 10.1038/s41440-019-0354-Z

87. Li S, Gao Y, Liu Y, Li J, Yang X, Hu R, et al. Myofibroblast-derived exosomes contribute to development of a susceptible substrate for atrial fibrillation. Cardiology. (2020) 145:324-32. doi: 10.1159/000505641

88. Cardin S, Li D, Thorin-Trescases N, Leung TK, Thorin E, Nattel S. Evolution of the atrial fibrillation substrate in experimental congestive heart failure: angiotensin-dependent and -independent pathways. Cardiovasc Res. (2003) 60:315-25. doi: 10.1016/j.cardiores.2003.08.014

89. Khan R, Sheppard R. Fibrosis in heart disease:understanding the role of transforming growth factorbeta in cardiomyopathy, valvular disease and arrhythmia. Immunology. (2006) 118:10-24. doi: 10.1111/j.1365-2567.2006.02336.x

90. Leask A. Potential therapeutic targets for cardiac fibrosis: TGFbeta, angiotensin, endothelin, CCN2, and PDGF, partners in fibroblast activation. Circ Res. (2010) 106:1675-80. doi: 10.1161/CIRCRESAHA.110.217737

91. Aimé-Sempé C, Folliguet T, Rücker-Martin C, Krajewska M, Krajewska $\mathrm{S}$, Heimburger $\mathrm{M}$, et al. Myocardial cell death in fibrillating and dilated human right atria. J Am Coll Cardiol. (1999) 34:1577-86. doi: 10.1016/s0735-1097(99)00382-4

92. Siwaponanan P, Keawvichit R, Udompunturak S, Hunnangkul S, Reesukumal K, Sukapirom K, et al. Altered profile of circulating microparticles in nonvalvular atrial fibrillation. Clin Cardiol. (2019) 42:425-31. doi: 10.1002/clc.23158

93. Yu RB, Li K, Wang G, Gao GM, Du JX. MiR-23 enhances cardiac fibroblast proliferation and suppresses fibroblast apoptosis via targeting TGF-betal in atrial fibrillation. Eur Rev Med Pharmacol Sci. (2019) 23:4419-24. doi: 10.26355/eurrev_201905_17950

94. Liu L, Zheng Q, Lee J, Ma Z, Zhu Q, Wang Z. PD-1/PD-L1 expression on $\mathrm{CD}(4+) \mathrm{T}$ cells and myeloid DCs correlates with the immune pathogenesis of atrial fibrillation. J Cell Mol Med. (2015) 19:1223-33. doi: $10.1111 /$ jcmm.12467

95. Miguel-Dos-Santos R, Moreira JBN, Loennechen JP, Wisløff U, Mesquita T. Exercising immune cells: the immunomodulatory role of exercise on atrial fibrillation. Prog Cardiovasc Dis. (2021) 15. doi: 10.1016/j.pcad.2021. 07.008

96. Hu YF, Chen YJ, Lin YJ, Chen SA. Inflammation and the pathogenesis of atrial fibrillation. Nat Rev Cardiol. (2015) 12:230-43. doi: $10.1038 /$ nrcardio.2015.2

97. Liew R, Khairunnisa K, Gu Y, Tee N, Yin NO, Naylynn TM, et al. Role of tumor necrosis factor- $\alpha$ in the pathogenesis of atrial fibrosis and development of an arrhythmogenic substrate. Circ J. (2013) 77:1171-9. doi: 10.1253/circj.cj-12-1155

98. Ryu K, Li L, Khrestian CM, Matsumoto N, Sahadevan J, Ruehr ML, et al. Effects of sterile pericarditis on connexins 40 and 43 in the atria: correlation with abnormal conduction and atrial arrhythmias. Am J Physiol Heart Circ Physiol. (2007) 293:H1231-41. doi: 10.1152/ajpheart.00607.2006

99. Rudolph V, Andrié RP, Rudolph TK, Friedrichs K, Klinke A, HirschHoffmann B, et al. Myeloperoxidase acts as a profibrotic mediator of atrial fibrillation. Nat Med. (2010) 16:470-4. doi: 10.1038/nm.2124

100. Hu YF, Yeh HI, Tsao HM, Tai CT, Lin YJ, Chang SL, et al. Impact of circulating monocyte CD36 level on atrial fibrillation and subsequent catheter ablation. Heart Rhythm. (2011) 8:650-6. doi: 10.1016/j.hrthm.2010.12.036

101. Hu YF, Yeh HI, Tsao HM, Tai CT, Lin YJ, Chang SL, et al. Electrophysiological correlation and prognostic impact of heat shock protein 27 in atrial fibrillation. Circ Arrhythm Electrophysiol. (2012) 5:334-40. doi: 10.1161/CIRCEP.111.965996

102. Luo J, Xu S, Li H, Gong M, Li Z, Liu B, et al. Long-term impact of the burden of new-onset atrial fibrillation in patients with acute myocardial infarction: results from the NOAFCAMI-SH registry. Europace. (2021) 23:196-204. doi: 10.1093/europace/euaa234

103. Podolecki T, Lenarczyk R, Kowalczyk J, Jedrzejczyk-Patej E, Swiatkowski A, Chodor P, et al. Significance of atrial fibrillation complicating stsegment elevation myocardial infarction. Am J Cardiol. (2017) 120:517-21. doi: 10.1016/j.amjcard.2017.05.017

104. Zusman O, Amit G, Gilutz H, Zahger D. The significance of new onset atrial fibrillation complicating acute myocardial infarction. Clin Res Cardiol. (2012) 101:17-22. doi: 10.1007/s00392-011-0357-5

105. Feistritzer HJ, Desch S, Zeymer U, Fuernau G, de Waha-Thiele S, Dudek $\mathrm{D}$, et al. Prognostic impact of atrial fibrillation in acute myocardial infarction and cardiogenic shock. Circ Cardiovasc Interv. (2019) 12:e007661. doi: 10.1161/CIRCINTERVENTIONS.118.007661

106. Gorenek B, Kudaiberdieva G. Atrial fibrillation in acute ST-elevation myocardial infarction: clinical and prognostic features. Curr Cardiol Rev. (2012) 8:281-9. doi: 10.2174/157340312803760857

107. Roldán V, Marín F, Díaz J, Gallego P, Jover E, Romera M, et al. High sensitivity cardiac troponin T and interleukin- 6 predict adverse cardiovascular events and mortality in anticoagulated patients with atrial fibrillation. J Thromb Haemost. (2012) 10:1500-7. doi: 10.1111/j.1538-7836.2012.04812.x

108. Thulin Å, Lindbäck J, Granger CB, Wallentin L, Lind L, Siegbahn A. Extracellular vesicles in atrial fibrillation and stroke. Thromb Res. (2020) 193:180-9. doi: 10.1016/j.thromres.2020.07.029

109. Wang H, Yan HM, Tang MX, Wang ZH, Zhong M, Zhang Y, et al. Increased serum levels of microvesicles in nonvalvular atrial fibrillation determinated by ELISA using a specific monoclonal antibody AD-1. Clin Chim Acta. (2010) 411:1700-4. doi: 10.1016/j.cca.2010.07.005

110. Sun C, Ni M, Song B, Cao L. Circulating circular RNAs: novel biomarkers for heart failure. Front Pharmacol. (2020) 11:560537. doi: 10.3389/fphar.2020.560537

111. Tao H, Zhang M, Yang JJ, Shi KH. MicroRNA-21 via dysregulation of WW domain-containing protein 1 regulate atrial fibrosis in atrial fibrillation. Heart Lung Circ. (2018) 27:104-13. doi: 10.1016/j.hlc.2016. 01.022 
112. Komal S, Yin JJ, Wang SH, Huang CZ, Tao HL, Dong JZ, et al. MicroRNAs: emerging biomarkers for atrial fibrillation. J Cardiol. (2019) 74:475-82. doi: 10.1016/j.jjcc.2019.05.018

113. Franco D, Aranega A, Dominguez JN. Non-coding RNAs and atrial fibrillation. Adv Exp Med Biol. (2020) 1229:311-25. doi: 10.1007/978-981-15-1671-9_19

114. Chen LL, Yang L. Regulation of circRNA biogenesis. RNA Biol. (2015) 12:381-8. doi: 10.1080/15476286.2015.1020271

115. Girmatsion Z, Biliczki P, Bonauer A, Wimmer-Greinecker G, Scherer M, Moritz A, et al. Changes in microRNA-1 expression and IK1 upregulation in human atrial fibrillation. Heart Rhythm. (2009) 6:1802-9. doi: 10.1016/j.hrthm.2009.08.035

116. Yang B, Lin H, Xiao J, Lu Y, Luo X, Li B, et al. The muscle-specific microRNA miR-1 $\mathrm{r}$ egulates cardiac arrhythmogenic potential by targeting GJA1 and KCNJ2. Nat Med. (2007) 13:486-91. doi: 10.1038/nm1569

117. Harada M, Luo X, Qi XY, Tadevosyan A, Maguy A, Ordog B, et al. Transient receptor potential canonical-3 channel-dependent fibroblast regulation in atrial fibrillation. Circulation. (2012) 126:2051-64. doi: 10.1161/CIRCULATIONAHA.112.121830

118. Luo X, Pan Z, Shan H, Xiao J, Sun X, Wang N, et al. MicroRNA-26 governs profibrillatory inward-rectifier potassium current changes in atrial fibrillation. J Clin Invest. (2013) 123:1939-51. doi: 10.1172/JCI62185

119. Chiang DY, Kongchan N, Beavers DL, Alsina KM, Voigt N, Neilson JR, et al. Loss of microRNA-106b-25 cluster promotes atrial fibrillation by enhancing ryanodine receptor type-2 expression and calcium release. Circ Arrhythm Electrophysiol. (2014) 7:1214-22. doi: 10.1161/CIRCEP.114. 001973

120. van Rooij E, Sutherland LB, Thatcher JE, DiMaio JM, Naseem RH, Marshall WS, et al. Dysregulation of microRNAs after myocardial infarction reveals a role of miR-29 in cardiac fibrosis. Proc Natl Acad Sci USA. (2008) 105:1302732. doi: 10.1073/pnas.0805038105

121. Dawson K, Wakili R, Ordög B, Clauss S, Chen Y, Iwasaki Y, et al. MicroRNA29: a mechanistic contributor and potential biomarker in atrial fibrillation. Circulation. (2013) 127:1466-75:1475e1-28. doi: 10.1161/CIRCULATIONAHA.112.001207

122. Duisters RF, Tijsen AJ, Schroen B, Leenders JJ, Lentink V, van der Made I, et al. miR-133 and miR-30 regulate connective tissue growth factor: implications for a role of microRNAs in myocardial matrix remodeling. Circ Res. (2009) 104:170-8. doi: 10.1161/CIRCRESAHA.108.182535

123. Chen Y, Wakili R, Xiao J, Wu CT, Luo X, Clauss S, et al. Detailed characterization of microRNA changes in a canine heart failure model: relationship to arrhythmogenic structural remodeling. J Mol Cell Cardiol. (2014) 77:113-24. doi: 10.1016/j.yjmcc.2014.10.001

124. Cheng WL, Kao YH, Chao TF, Lin YK, Chen SA, Chen YJ. MicroRNA133 suppresses ZFHX3-dependent atrial remodelling and arrhythmia. Acta Physiol. (2019) 227:e13322. doi: 10.1111/apha.13322

125. Shan H, Zhang Y, Lu Y, Zhang Y, Pan Z, Cai B, et al. Downregulation of miR-133 and miR-590 contributes to nicotine-induced atrial remodelling in canines. Cardiovasc Res. (2009) 83:465-72. doi: 10.1093/cvr/cvp130

126. Gao Q, Xu L, Yang Q, Guan TJ. MicroRNA-21 contributes to high glucoseinduced fibrosis in peritoneal mesothelial cells in rat models by activation of the Ras-MAPK signaling pathway via Sprouty-1. J Cell Physiol. (2019) 234:5915-25. doi: 10.1002/jcp.26941

127. Thum T, Gross C, Fiedler J, Fischer T, Kissler S, Bussen M, et al. MicroRNA21 contributes to myocardial disease by stimulating MAP kinase signalling in fibroblasts. Nature. (2008) 456:980-4. doi: 10.1038/nature07511

128. Adam O, Löhfelm B, Thum T, Gupta SK, Puhl SL, Schäfers HJ, et al. Role of miR-21 in the pathogenesis of atrial fibrosis. Basic Res Cardiol. (2012) 107:278. doi: 10.1007/s00395-012-0278-0

129. McManus DD, Lin H, Tanriverdi K, Quercio M, Yin X, Larson MG, et al. Relations between circulating microRNAs and atrial fibrillation: data from the Framingham Offspring Study. Heart Rhythm. (2014) 11:663-9. doi: 10.1016/j.hrthm.2014.01.018

130. Lu Y, Zhang Y, Wang N, Pan Z, Gao X, Zhang F, et al. MicroRNA-328 contributes to adverse electrical remodeling in atrial fibrillation. Circulation. (2010) 122:2378-87. doi: 10.1161/CIRCULATIONAHA.110.958967

131. Ling TY, Wang XL, Chai Q, Lau TW, Koestler CM, Park SJ, et al. Regulation of the SK3 channel by microRNA-499-potential role in atrial fibrillation. Heart Rhythm. (2013) 10:1001-9. doi: 10.1016/j.hrthm.2013. 03.005

132. Wang JX, Jiao JQ, Li Q, Long B, Wang K, Liu JP, et al. miR-499 regulates mitochondrial dynamics by targeting calcineurin and dynamin-related protein-1. Nat Med. (2011) 17:71-8. doi: 10.1038/nm.2282

133. De Toro J, Herschlik L, Waldner C, Mongini C. Emerging roles of exosomes in normal and pathological conditions: new insights for diagnosis and therapeutic applications. Front Immunol. (2015) 6:203. doi: 10.3389/fimmu.2015.00203

134. van Rooij E, Sutherland LB, Qi X, Richardson JA, Hill J, Olson EN. Control of stress-dependent cardiac growth and gene expression by a microRNA. Science. (2007) 316:575-9. doi: 10.1126/science.1139089

135. Callis TE, Pandya K, Seok HY, Tang RH, Tatsuguchi M, Huang ZP, et al. MicroRNA-208a is a regulator of cardiac hypertrophy and conduction in mice. J Clin Invest. (2009) 119:2772-86. doi: 10.1172/JCI36154

136. Satoh M, Minami Y, Takahashi Y, Tabuchi T, Nakamura M. Expression of microRNA-208 is associated with adverse clinical outcomes in human dilated cardiomyopathy. J Card Fail. (2010) 16:404-10. doi: 10.1016/j.cardfail.2010.01.002

137. Qian C, Li H, Chang D, Wei B, Wang Y. Identification of functional lncRNAs in atrial fibrillation by integrative analysis of the lncRNA-mRNA network based on competing endogenous RNAs hypothesis. J Cell Physiol. (2019) 234:11620-30. doi: 10.1002/jcp.27819

138. Du J, Li Z, Wang X, Li J, Liu D, Wang X, et al. Long noncoding RNA TCONS00106987 promotes atrial electrical remodelling during atrial fibrillation by sponging miR-26 to regulate KCNJ2. J Cell Mol Med. (2020) 24:12777-88. doi: $10.1111 /$ jcmm.15869

139. Yao L, Zhou B, You L, Hu H, Xie R. LncRNA MIAT/miR-133a-3p axis regulates atrial fibrillation and atrial fibrillation-induced myocardial fibrosis. Mol Biol Rep. (2020) 47:2605-17. doi: 10.1007/s11033-020-05347-0

140. Zhao JB, Zhu N, Lei YH, Zhang CJ, Li YH. Modulative effects of lncRNA TCONS_00202959 on autonomic neural function and myocardial functions in atrial fibrillation rat model. Eur Rev Med Pharmacol Sci. (2018) 22:8891-7. doi: 10.26355/eurrev_201812_16658

141. Xu Y, Huang R, Gu J, Jiang W. Identification of long non-coding RNAs as novel biomarker and potential therapeutic target for atrial fibrillation in old adults. Oncotarget. (2016) 7:10803-11. doi: 10.18632/oncotarget. 7514

142. Ruan ZB, Wang F, Bao TT, Yu QP, Chen GC, Zhu L. Genome-wide analysis of circular RNA expression profiles in patients with atrial fibrillation. Int $J$ Clin Exp Pathol. (2020) 13:1933-50.

143. Shi J, Chen L, Chen S, Wu B, Yang K, Hu X. Circulating long noncoding RNA, GAS5, as a novel biomarker for patients with atrial fibrillation. J Clin Lab Anal. (2021) 35:e23572. doi: 10.1002/jcla.23572

144. Lu J, Xu FQ, Guo JJ, Lin PL, Meng Z, Hu LG, et al. Long noncoding RNA GAS5 attenuates cardiac fibroblast proliferation in atrial fibrillation via repressing ALK5. Eur Rev Med Pharmacol Sci. (2019) 23:7605-10. doi: 10.26355/eurrev_201909_18883

145. Ruan Z, Sun X, Sheng H, Zhu L. Long non-coding RNA expression profile in atrial fibrillation. Int J Clin Exp Pathol. (2015) 8:8402-10.

146. Zhao L, Ma Z, Guo Z, Zheng M, Li K, Yang X. Analysis of long non-coding RNA and mRNA profiles in epicardial adipose tissue of patients with atrial fibrillation. Biomed Pharmacother. (2020) 121:109634. doi: 10.1016/j.biopha.2019.109634

147. Wu N, Li J, Chen X, Xiang Y, Wu L, Li C, et al. Identification of long noncoding RNA and circular RNA expression profiles in atrial fibrillation. Heart Lung Circ. (2020) 29:e157-67. doi: 10.1016/j.hlc.2019.10.018

148. Cao F, Li Z, Ding WM, Yan L, Zhao QY. LncRNA PVT1 regulates atrial fibrosis via miR-128-3p-SP1-TGF- $\beta 1$-Smad axis in atrial fibrillation. Mol Med. (2019) 25:7. doi: 10.1186/s10020-019-0074-5

149. Dai H, Zhao N, Liu H, Zheng Y, Zhao L. LncRNA nuclear-enriched abundant transcript 1 regulates atrial fibrosis via the miR-320/NPAS2 axis in atrial fibrillation. Front Pharmacol. (2021) 12:647124. doi: 10.3389/fphar.2021.647124

150. Chen Q, Feng C, Liu Y, Li QF, Qiu FY, Wang MH, et al. Long non-coding RNA PCAT-1 promotes cardiac fibroblast proliferation via upregulating TGF- $\beta 1$. Eur Rev Med Pharmacol Sci. (2020) 24:8247. doi: 10.26355/eurrev_202008_22588 
151. Wang LY, Shen H, Yang Q, Min J, Wang Q, Xi W, et al. LncRNALINC00472 contributes to the pathogenesis of atrial fibrillation (Af) by reducing expression of JP2 and RyR2 via miR-24. Biomed Pharmacother. (2019) 120:109364. doi: 10.1016/j.biopha.2019.109364

152. Dai W, Chao X, Li S, Zhou S, Zhong G, Jiang Z. Long noncoding RNA HOTAIR functions as a competitive endogenous RNA to regulate Connexin43 remodeling in atrial fibrillation by sponging MicroRNA-613. Cardiovasc Ther. (2020) 2020:5925342. doi: 10.1155/2020/5925342

153. Wu J, Han D, Shi R, Chen M, Sun J, Tian H, et al. Identification of atrial fibrillation-associated lncRNAs in atria from patients with rheumatic mitral valve disease. Microsc Res Tech. (2019) 82:1136-44. doi: 10.1002/jemt.23261

154. Mei B, Liu H, Yang S, Liang MY, Yue Y, Huang SQ, et al. Long noncoding RNA expression profile in permanent atrial fibrillation patients with rheumatic heart disease. Eur Rev Med Pharmacol Sci. (2018) 22:6940-7. doi: 10.26355/eurrev_201810_16165

155. Li Z, Wang X, Wang W, Du J, Wei J, Zhang Y, et al. Altered long non-coding RNA expression profile in rabbit atria with atrial fibrillation: TCONS_00075467 modulates atrial electrical remodeling by sponging miR-328 to regulate CACNA1C. J Mol Cell Cardiol. (2017) 108:73-85. doi: 10.1016/j.yjmcc.2017.05.009

156. Chen G, Guo H, Song Y, Chang H, Wang S, Zhang M, et al. Long noncoding RNA AK055347 is upregulated in patients with atrial fibrillation and regulates mitochondrial energy production in myocardiocytes. Mol Med Rep. (2016) 14:5311-7. doi: 10.3892/mmr.2016.5893

157. Jiang XY, Ning QL. Expression profiling of long noncoding RNAs and the dynamic changes of lncRNA-NR024118 and Cdkn1c in angiotensin II-treated cardiac fibroblasts. Int J Clin Exp Pathol. (2014) 7:1325-36.

158. Su Y, Li L, Zhao S, Yue Y, Yang S. The long noncoding RNA expression profiles of paroxysmal atrial fibrillation identified by microarray analysis. Gene. (2018) 642:125-34. doi: 10.1016/j.gene.2017.11.025

159. Wang W, Wang X, Zhang Y, Li Z, Xie X, Wang J, et al. Transcriptome analysis of canine cardiac fat pads: involvement of two novel long non-coding RNAs in atrial fibrillation neural remodeling. J Cell Biochem. (2015) 116:809-21. doi: $10.1002 /$ jcb. 25037

160. Yu XJ, Zou LH, Jin JH, Xiao F, Li L, Liu N, et al. Long noncoding RNAs and novel inflammatory genes determined by RNA sequencing in human lymphocytes are up-regulated in permanent atrial fibrillation. Am J Transl Res. (2017) 9:2314-26.

161. Sun H, Shao Y. Transcriptome analysis reveals key pathways that vary in patients with paroxysmal and persistent atrial fibrillation. Exp Ther Med. (2021) 21:571. doi: 10.3892/etm.2021.10003

162. Ke ZP, Xu YJ, Wang ZS, Sun J. RNA sequencing profiling reveals key mRNAs and long noncoding RNAs in atrial fibrillation. J Cell Biochem. (2019). doi: 10.1002/jcb.29504. [Epub ahead of print].

163. Shangguan W, Liang X, Shi W, Liu T, Wang M, Li G. Identification and characterization of circular RNAs in rapid atrial pacing dog atrial tissue. Biochem Biophys Res Commun. (2018) 506:1-6. doi: 10.1016/j.bbrc.2018.05.082

164. Gao Y, Liu Y, Fu Y, Wang Q, Liu Z, Hu R, et al. The potential regulatory role of hsa_circ_0004104 in the persistency of atrial fibrillation by promoting cardiac fibrosis via TGF- $\beta$ pathway. BMC Cardiovasc Disord. (2021) 21:25. doi: 10.1186/s12872-021-01847-4

165. Zhang Y, Shen H, Wang P, Min J, Yu Y, Wang Q, et al. Identification and characterization of circular RNAs in atrial appendage of patients with atrial fibrillation. Exp Cell Res. (2020) 389:111821. doi: 10.1016/j.yexcr.2020.111821

166. Zhang PP, Sun J, Li W. Genome-wide profiling reveals atrial fibrillationrelated circular RNAs in atrial appendages. Gene. (2020) 728:144286. doi: 10.1016/j.gene.2019.144286

167. Zhang Y, Ke X, Liu J, Ma X, Liu Y, Liang D, et al. Characterization of circRNAassociated ceRNA networks in patients with nonvalvular persistent atrial fibrillation. Mol Med Rep. (2019) 19:638-50. doi: 10.3892/mmr.2018.9695

168. Hu M, Wei X, Li M, Tao L, Wei L, Zhang M, et al. Circular RNA expression profiles of persistent atrial fibrillation in patients with rheumatic heart disease. Anatol J Cardiol. (2019) 21:2-10. doi: 10.14744/AnatolJCardiol.2018.35902
169. Liu T, Zhang G, Wang Y, Rao M, Zhang Y, Guo A, et al. Identification of circular RNA-MicroRNA-messenger RNA regulatory network in atrial fibrillation by integrated analysis. Biomed Res Int. (2020) 2020:8037273. doi: 10.1155/2020/8037273

170. Hu X, Chen L, Wu S, Xu K, Jiang W, Qin M, et al. Integrative analysis reveals key circular RNA in atrial fibrillation. Front Genet. (2019) 10:108. doi: 10.3389/fgene.2019.00108

171. Vasquez C, Mohandas P, Louie KL, Benamer N, Bapat AC, Morley GE. Enhanced fibroblast-myocyte interactions in response to cardiac injury. Circ Res. (2010) 107:1011-20. doi: 10.1161/CIRCRESAHA.110.227421

172. Cooley N, Cowley MJ, Lin RC, Marasco S, Wong C, et al. Influence of atrial fibrillation on microRNA expression profiles in left and right atria from patients with valvular heart disease. Physiol Genomics. (2012) 44:211-9. doi: 10.1152/physiolgenomics.00111.2011

173. Sluijter JPG, Davidson SM, Boulanger CM, Buzás EI, de Kleijn DPV, Engel FB et al. Extracellular vesicles in diagnostics and therapy of the ischaemic heart: position paper from the Working Group on Cellular Biology of the Heart of the European Society of Cardiology. Cardiovasc Res. (2018) 114:19-34. doi: $10.1093 / \mathrm{cvr} / \mathrm{cvx} 211$

174. Kita S, Maeda N, Shimomura I. Interorgan communication by exosomes, adipose tissue, and adiponectin in metabolic syndrome. J Clin Invest. (2019) 129:4041-9. doi: 10.1172/JCI129193

175. January CT, Wann LS, Alpert JS, Calkins H, Cigarroa JE, Cleveland JC Jr, et al. ACC/AHA Task Force Members. 2014 AHA/ACC/HRS guideline for the management of patients with atrial fibrillation: executive summary: a report of the American College of Cardiology/American Heart Association Task Force on Practice Guidelines and the Heart Rhythm Society. Circulation. (2014) 130:2071-104. doi: 10.1161/CIR.0000000000000040

176. Zhao ZH, Luo J, Li HX, Wang SH, Li XM. SOX2-mediated inhibition of miR-223 contributes to STIM1 activation in phenylephrine-induced hypertrophic cardiomyocytes. Mol Cell Biochem. (2018) 443:47-56. doi: 10.1007/s11010-017-3209-4

177. Goren Y, Meiri E, Hogan C, Mitchell H, Lebanony D, Salman N, et al. Relation of reduced expression of MiR-150 in platelets to atrial fibrillation in patients with chronic systolic heart failure. Am J Cardiol. (2014) 113:976-81. doi: 10.1016/j.amjcard.2013.11.060

178. Wei Z, Bing Z, Shaohuan Q, Yanran W, Shuo S, Bi T, et al. Expression of miRNAs in plasma exosomes derived from patients with atrial fibrillation. Clin Cardiol. (2020) 43:1450-9. doi: 10.1002/clc.23461

179. Wang S, Min J, Yu Y, Yin L, Wang Q, Shen H, et al. Differentially expressed miRNAs in circulating exosomes between atrial fibrillation and sinus rhythm. J Thorac Dis. (2019) 11:4337-48. doi: 10.21037/jtd.2019.09.50

180. Mun D, Kim H, Kang JY, Park H, Park H, Lee SH, et al. Expression of miRNAs in circulating exosomes derived from patients with persistent atrial fibrillation. FASEB J. (2019) 33:5979-89. doi: 10.1096/fj.201801758R

181. Liu L, Chen Y, Shu J, Tang CE, Jiang Y, Luo F. Identification of microRNAs enriched in exosomes in human pericardial fluid of patients with atrial fibrillation based on bioinformatic analysis. J Thorac Dis. (2020) 12:5617-27. doi: 10.21037/jtd-20-2066

182. Qi Z, Wu D, Li M, Yan Z, Yang X, Ji N, et al. The pluripotent role of exosomes in mediating non-coding RNA in ventricular remodeling after myocardial infarction. Life Sci. (2020) 254:117761. doi: 10.1016/j.lfs.2020.117761

183. Li J, Rohailla S, Gelber N, Rutka J, Sabah N, Gladstone RA, et al. MicroRNA144 is a circulating effector of remote ischemic preconditioning. Basic Res Cardiol. (2014) 109:423. doi: 10.1007/s00395-014-0423-z

184. Gray WD, French KM, Ghosh-Choudhary S, Maxwell JT, Brown ME, Platt $\mathrm{MO}$, et al. Identification of therapeutic covariant microRNA clusters in hypoxia-treated cardiac progenitor cell exosomes using systems biology. Circ Res. (2015) 116:255-63. doi: 10.1161/CIRCRESAHA.116.304360

185. Feng Y, Huang W, Wani M, Yu X, Ashraf M. Ischemic preconditioning potentiates the protective effect of stem cells through secretion of exosomes by targeting Mecp2 via miR-22. PLoS ONE. (2014) 9:e88685. doi: 10.1371/journal.pone.0088685

186. Khan M, Nickoloff E, Abramova T, Johnson J, Verma S, Krishnamurthy, et al. Embryonic stem cell-derived exosomes promote endogenous repair mechanisms and enhance cardiac function following myocardial infarction. Circulation Res. (2015) 117:52-64. doi: 10.1161/CIRCRESAHA.117.305990 
187. Yuan J, Liu H, Gao W, Zhang L, Ye Y, Yuan L, et al. MicroRNA-378 suppresses myocardial fibrosis through a paracrine mechanism at the early stage of cardiac hypertrophy following mechanical stress. Theranostics. (2018) 8:2565-82. doi: 10.7150/thno.22878

188. Wang X, Huang W, Liu G, Cai W, Millard RW, Wang Y, et al. Cardiomyocytes mediate anti-angiogenesis in type 2 diabetic rats through the exosomal transfer of miR-320 into endothelial cells. J Mol Cell Cardiol. (2014) 74:139-50. doi: 10.1016/j.yjmcc.2014.05.001

189. Xu C, Hu Y, Hou L, Ju J, Li X, Du N, et al. $\beta$-Blocker carvedilol protects cardiomyocytes against oxidative stress-induced apoptosis by upregulating miR-133 expression. J Mol Cell Cardiol. (2014) 75:111-21. doi: 10.1016/j.yjmcc.2014.07.009

190. Venkat P, Cui C, Chen Z, Chopp M, Zacharek A, Landschoot-Ward J, et al. CD133+Exosome treatment improves cardiac function after stroke in type 2 diabetic mice. Transl Stroke Res. (2021) 12:112-24. doi: 10.1007/s12975-020-00807-y

191. Wang C, Zhang C, Liu L, Xi A, Chen B, Li Y, et al. Macrophage-derived mir-155-containing exosomes suppress fibroblast proliferation and promote fibroblast inflammation during cardiac injury. Mol Ther. (2017) 25:192-204. doi: 10.1016/j.ymthe.2016.09.001

192. Luo Q, Guo D, Liu G, Chen G, Hang M, Jin M. Exosomes from MiR-126overexpressing adscs are therapeutic in relieving acute myocardial ischaemic injury. Cell Physiol Biochem. (2017) 44:2105-16. doi: 10.1159/000485949

193. Moghiman T, Barghchi B, Esmaeili SA, Shabestari MM, Tabaee SS, MomtaziBorojeni AA. Therapeutic angiogenesis with exosomal microRNAs: an effectual approach for the treatment of myocardial ischemia. Heart Fail Rev. (2021) 26:205-13. doi: 10.1007/s10741-020-10001-9

194. Wang L, Liu J, Xu B, Liu YL, Liu Z. Reduced exosome miR-425 and miR744 in the plasma represents the progression of fibrosis and heart failure. Kaohsiung J Med Sci. (2018) 34:626-33. doi: 10.1016/j.kjms.2018.05.008

195. Wang B, Zhang A, Wang H, Klein JD, Tan L, Wang ZM, et al. miR26a limits muscle wasting and cardiac fibrosis through exosome-mediated microRNA transfer in chronic kidney disease. Theranostics. (2019) 9:186477. doi: 10.7150/thno.29579

196. Xiao J, Pan Y, Li XH, Yang XY, Feng YL, Tan HH, et al. Cardiac progenitor cell-derived exosomes prevent cardiomyocytes apoptosis through exosomal miR-21 by targeting PDCD4. Cell Death Dis. (2016) 7:e2277. doi: 10.1038/cddis.2016.181

197. Zhou Y, Zhao J, Wang LH, Wang YC, Zhong ZsW, et al. Enhanced cardioprotection by human endometrium mesenchymal stem cells driven by exosomal microRNA-21. Stem Cells Transl Med. (2017) 6:209-22. doi: 10.5966/sctm.2015-0386

198. Chen A, Wen J, Lu C, Lin B, Xian S, Huang F, et al. Inhibition of miR-155-5 p attenuates the valvular damage induced by rheumatic heart disease. Int $\mathrm{J} \mathrm{Mol}$ Med. (2020) 45:429-40. doi: 10.3892/ijmm.2019.4420

199. Han P, Li W, Lin CH, Yang J, Shang C, Nuernberg ST, et al. A long noncoding RNA protects the heart from pathological hypertrophy. Nature. (2014) 514:102-6. doi: 10.1038/nature13596

200. Yu B, Kim HW, Gong M, Wang J, Millard RW, Wang Y, et al. Exosomes secreted from GATA-4 overexpressing mesenchymal stem cells serve as a reservoir of anti-apoptotic microRNAs for cardioprotection. Int J Cardiol. (2015) 182:349-60. doi: 10.1016/j.ijcard.2014.12.043

201. Wen M, Gong Z, Huang C, Liang Q, Xu M, Wang L, et al. Plasma exosomes induced by remote ischaemic preconditioning attenuate myocardial ischaemia/reperfusion injury by transferring miR-24. Cell Death Dis. (2018) 9:320. doi: 10.1038/s41419-018-0274-x

202. Wen Z, Mai Z, Zhu X, Wu T, Chen Y, Geng D, et al. Mesenchymal stem cellderived exosomes ameliorate cardiomyocyte apoptosis in hypoxic conditions through microRNA144 by targeting the PTEN/AKT pathway. Stem Cell Res Ther. (2020) 11:36. doi: 10.1186/s13287-020-1563-8

203. Li M, Ding W, Tariq MA, Chang W, Zhang X, Xu W, et al. A circular transcript of ncxl gene mediates ischemic myocardial injury by targeting miR-133a-3p. Theranostics. (2018) 8:5855-69. doi: 10.7150/thno. 27285

204. Xu JF, Yang GH, Pan XH, Zhang SJ, Zhao C, Qiu BS, et al. Altered microRNA expression profile in exosomes during osteogenic differentiation of human bone marrow-derived mesenchymal stem cells. PLoS ONE. (2014) 9:e114627. doi: 10.1371/journal.pone.0114627
205. Barile L, Lionetti V, Cervio E, Matteucci M, Gherghiceanu M, Popescu LM, et al. Extracellular vesicles from human cardiac progenitor cells inhibit cardiomyocyte apoptosis and improve cardiac function after myocardial infarction. Cardiovasc Res. (2014) 103:530-41. doi: 10.1093/cvr/cvu167

206. Yu B, Gong M, Wang Y, Millard RW, Pasha Z, Yang Y, et al. Cardiomyocyte protection by GATA-4 gene engineered mesenchymal stem cells is partially mediated by translocation of miR-221 in microvesicles. PLoS ONE. (2013) 8:e73304. doi: 10.1371/journal.pone.0073304s

207. Li Y, Zhou J, Zhang O, Wu X, Guan X, Xue Y, et al. Bone marrow mesenchymal stem cells-derived exosomal microRNA-185 represses ventricular remolding of mice with myocardial infarction by inhibiting SOCS2. Int Immunopharmacol. (2020) 80:106156. doi: 10.1016/j.intimp.2019.106156

208. Zhu LP, Tian T, Wang JY, He JN, Chen T, Pan M, et al. Hypoxia-elicited mesenchymal stem cell-derived exosomes facilitates cardiac repair through miR-125b-mediated prevention of cell death in myocardial infarction. Theranostics. (2018) 8:6163-77. doi: 10.7150/thno.28021

209. Song Y, Zhang C, Zhang J, Jiao Z, Dong N, Wang G, et al. Localized injection of miRNA-21-enriched extracellular vesicles effectively restores cardiac function after myocardial infarction. Theranostics. (2019) 9:2346-60. doi: 10.7150/thno. 29945

210. Ibrahim AG, Cheng K, Marbán E. Exosomes as critical agents of cardiac regeneration triggered by cell therapy. Stem Cell Rep. (2014) 2:606-19. doi: 10.1016/j.stemcr.2014.04.006

211. Wang W, Zheng Y, Wang M, Yan M, Jiang J, Li Z, et al. Exosomes derived miR-126 attenuates oxidative stress and apoptosis from ischemia and reperfusion injury by targeting ERRFI1. Gene. (2019) 690:75-80. doi: 10.1016/j.gene.2018.12.044

212. Luo H, Li X, Li T, Zhao L, He J, Zha L, et al. microRNA-423-3p exosomes derived from cardiac fibroblasts mediates the cardioprotective effects of ischaemic post-conditioning. Cardiovasc Res. (2019) 115:1189-204. doi: $10.1093 / \mathrm{cvr} / \mathrm{cvy} 231$

213. Wei Z, Qiao S, Zhao J, Liu Y, Li Q, Wei Z, et al. miRNA-181a over-expression in mesenchymal stem cell-derived exosomes influenced inflammatory response after myocardial ischemia-reperfusion injury. Life Sci. (2019) 232:116632. doi: 10.1016/j.lfs.2019.116632

214. Tung SL, Boardman DA, Sen M, Letizia M, Peng Q, Cianci N, et al. Regulatory $\mathrm{T}$ cell-derived extracellular vesicles modify dendritic cell function. Sci Rep. (2018) 8:6065. doi: 10.1038/s41598-018-24531-8

215. Zhong X, Gao W, Wu R, Liu H, Ge J. Dendritic cell exosome-shuttled miRNA146a regulates exosome-induced endothelial cell inflammation by inhibiting IRAK-1: a feedback control mechanism. Mol Med Rep. (2019) 20:5315-23. doi: 10.3892/mmr.2019.10749

216. de Couto G, Gallet R, Cambier L, Jaghatspanyan E, Makkar N, Dawkins J, et al. Exosomal MicroRNA transfer into macrophages mediates cellular postconditioning. Circulation. (2017) 136:200-14. doi: 10.1161/CIRCULATIONAHA.116.024590

217. Zhao J, Li X, Hu J, Chen F, Qiao S, Sun X, et al. Mesenchymal stromal cell-derived exosomes attenuate myocardial ischaemia-reperfusion injury through miR-182 regulated macrophage polarization. Cardiovasc Res. (2019) 115:1205-16. doi: 10.1093/cvr/cvz040

218. Li J, Tan M, Xiang Q, Zhou Z, Yan H. Thrombin-activated platelet-derived exosomes regulate endothelial cell expression of ICAM-1 via microRNA223 during the thrombosis-inflammation response. Thromb Res. (2017) 154:96-105. doi: 10.1016/j.thromres.2017.04.016

219. Wang N, Chen C, Yang D, Liao Q, Luo H, Wang X, et al. Mesenchymal stem cells-derived extracellular vesicles, via miR-210, improve infarcted cardiac function by promotion of angiogenesis. Biochim Biophys Acta Mol Basis Dis. (2017) 1863:2085-92. doi: 10.1016/j.bbadis.2017.02.023

220. Hu S, Huang M, Li Z, Jia F, Ghosh Z, Lijkwan MA, et al. MicroRNA-210 as a novel therapy for treatment of ischemic heart disease. Circulation. (2010) 122:S12 4-31. doi: 10.1161/CIRCULATIONAHA.109.928424

221. Ma T, Chen Y, Chen Y, Meng Q, Sun J, Shao L, et al. MicroRNA132, Delivered by mesenchymal stem cell-derived exosomes, promote angiogenesis in myocardial infarction. Stem Cells Int. (2018) 2018:3290372. doi: $10.1155 / 2018 / 3290372$

222. Sun D, Zhuang X, Xiang X, Liu Y, Zhang S, Liu C, et al. A novel nanoparticle drug delivery system: the anti-inflammatory activity of curcumin is 
enhanced when encapsulated in exosomes. Mol Ther. (2010) 18:1606-14. doi: $10.1038 / \mathrm{mt} .2010 .105$

223. Tikhomirov R, Donnell BR, Catapano F, Faggian G, Gorelik J, Martelli F, et al. Exosomes: from potential culprits to new therapeutic promise in the setting of cardiac fibrosis. Cells. (2020) 9:592. doi: 10.3390/cells9030592

224. Sato YT, Umezaki K, Sawada S, Mukai SA, Sasaki Y, Harada N, et al. Engineering hybrid exosomes by membrane fusion with liposomes. Sci Rep. (2016) 6:21933. doi: 10.1038/srep21933

225. Alvarez-Erviti L, Seow Y, Yin H, Betts C, Lakhal S, Wood MJ. Delivery of siRNA to the mouse brain by systemic injection of targeted exosomes. Nat Biotechnol. (2011) 29:341-5. doi: 10.1038/nbt.1807

226. Vandergriff A, Huang K, Shen D, Hu S, Hensley MT, Caranasos TG, et al. Targeting regenerative exosomes to myocardial infarction using cardiac homing peptide. Theranostics. (2018) 8:1869-78. doi: 10.7150/thno.20524

227. Yim N, Ryu SW, Choi K, Lee KR, Lee S, Choi H, et al. Exosome engineering for efficient intracellular delivery of soluble proteins using optically reversible protein-protein interaction module. Nat Commun. (2016) 7:12277. doi: 10.1038/ncomms12277

228. Balbi C, Vassalli G. Exosomes: beyond stem cells for cardiac protection and repair. Stem Cells. (2020) 38:1387-99. doi: 10.1002/stem.3261

229. Liu B, Lee BW, Nakanishi K, Villasante A, Williamson R, Metz J, et al. Cardiac recovery via extended cell-free delivery of extracellular vesicles secreted by cardiomyocytes derived from induced pluripotent stem cells. Nat Biomed Eng. (2018) 2:293-303. doi: 10.1038/s41551-018-0229-7

230. Zarà $\mathrm{M}$, Amadio $\mathrm{P}$, Campodonico $\mathrm{J}$, Sandrini $\mathrm{L}$, Barbieri SS. Exosomes in cardiovascular diseases. Diagnostics. (2020) 10:943. doi: 10.3390/diagnosticcs10110943
231. Pan J, Alimujiang M, Chen Q, Shi H, Luo X. Exosomes derived from miR-146amodified adipose-derived stem cells attenuate acute myocardial infarction-induced myocardial damage via downregulation of early growth response factor 1. J Cell Biochem. (2019) 120:4433-43. doi: 10.1002/jcb. 27731

232. He S, Wu C, Xiao J, Li D, Sun Z, Li M. Endothelial extracellular vesicles modulate the macrophage phenotype: potential implications in atherosclerosis. Scand J Immunol. (2018) 87:e12648. doi: 10.1111/sji.12648

Conflict of Interest: The authors declare that the research was conducted in the absence of any commercial or financial relationships that could be construed as a potential conflict of interest.

Publisher's Note: All claims expressed in this article are solely those of the authors and do not necessarily represent those of their affiliated organizations, or those of the publisher, the editors and the reviewers. Any product that may be evaluated in this article, or claim that may be made by its manufacturer, is not guaranteed or endorsed by the publisher.

Copyright $\odot 2021$ Chen, Chen, Cheng, Zou, Pang, Ling, Xu and Zhu. This is an open-access article distributed under the terms of the Creative Commons Attribution License (CC BY). The use, distribution or reproduction in other forums is permitted, provided the original author(s) and the copyright owner(s) are credited and that the original publication in this journal is cited, in accordance with accepted academic practice. No use, distribution or reproduction is permitted which does not comply with these terms. 